\title{
DESIGN AND ANALYSIS OF CONCRETE REACTOR VESSELS: NEW DEVELOPMENTS, PROBLEMS AND TRENDS *
}

\author{
Zdeněk P. BAŽANT \\ Professor of Civil Engineering and Director, Center for Concrete and Geomaterials, The Technological Institute, \\ Northwestern University, Evanston, Illinois 60201, USA
}

Received 22 August 1983

\begin{abstract}
This lecture reviews new developments in analysis and design of prestressed concrete reactor vessels (PCRV). After a brief assessment of the current status and experience, the advantages, disadvantages, and especially the safety features of PCRV, are discussed. Attention is then focused on the design of penetrations and openings, and on the design for high-temperature resistance - areas in which further developments are needed. Various possible designs for high-temperature exposure of concrete in a hypothetical accident are analyzed. Considered are not only PCRVs for gas-cooled reactors (GCR), but also guard vessels for liquid metal fast breeder reactors (LMFBR), for which designs mitigating the adverse effects of molten sodium, molten steel, and core melt are surveyed. Realistic analysis of these problems requires further development in the knowledge of material behavior and its mathematical modeling. Recent advances in the modeling of high-temperature response of concrete, including pore water transfer, pore pressure, creep and shrinkage are outlined. This is followed by a discussion of new developments in the analysis of cracking of concrete, where the need of switching from stress criteria to energy criteria for fracture is emphasized. The lecture concludes with a brief discussion of long-time behavior, the effect of aging, and probabilistic analysis of creep.
\end{abstract}

\section{Introduction}

Prestressed concrete reactor vessels (PCRV) represent today a mature and proven technology. The cumulative experience exceeds 600 reactor years of operation. Altogether, 27 PCRVs have been built so far, a few of which still await commissioning for operation. In France, the early leader in this technology [1-3], there are 6 PCRVs: Marcoule - 2 (the first vessel was put in operation in 1960), Chinon, St Laurent - 2, Bugey. 18 vessels have been built in the United Kingdom [4,5]; Oldbury - 2, Wylfa - 2, Hinkley Pt. B - 2, Hunteston B - 2, Dungeness B - 2, Hartlepool - 2, Heysham - 4, and Torness - 2; one in Spain; Vandellos; one in the United States: Fort St Vrain (high-temperature gas cooled reactor - HTGR); and one in West Germany: Schmehausen THTR (Thorium high-temperature pebble-bed reactor).

- Invited lecture of Division $\mathbf{H}$ at the 7th International Conference on Structural Mechanics in Reactor Technology (SMiRT-7), Chicago, Illinois, USA, August 22-26, 1983.
PCRVs were originally developed for gas-cooled reactors. For these, a prestressed vessel, not necessarily a concrete vessel but possibly a prestressed cast iron vessel, seems to represent the only practical choice. Due to the large internal operating pressures in these reactors, which equal 4.36 MPa for the latest British advanced $\mathrm{CO}_{2}$-cooled reactors (Heysham 2, Torness) and 4.86 $\mathrm{MPa}$ for the helium-cooled HTGR at Fort St Vrain, impracticably thick walls would be required for a steel vessel. PCRVs are also considered for the gas-cooled breeder reactors as well as the smaller, modular high-temperature reactors for industrial process heat. PCRVs designs have been prepared for light water reactors, and recently, as more severe hypothetical core disruptive accidents are being postulated, a PCRV appears to have certain merits for liquid metal fast breeder reactors (LMFBR) even though the operating pressure is nearly atmospheric. Finally, PCRV designs have been studied for coal gasifiers, for which they would permit vessels of much larger sizes and internal pressures than currently used.

The present lecture attempts to discuss the safety aspects of PCRVs and outline some new advances in

0029-5493/84/\$03.00 (C) Elsevier Science Publishers B.V. (North-Holland Physics Publishing Division) 
a)

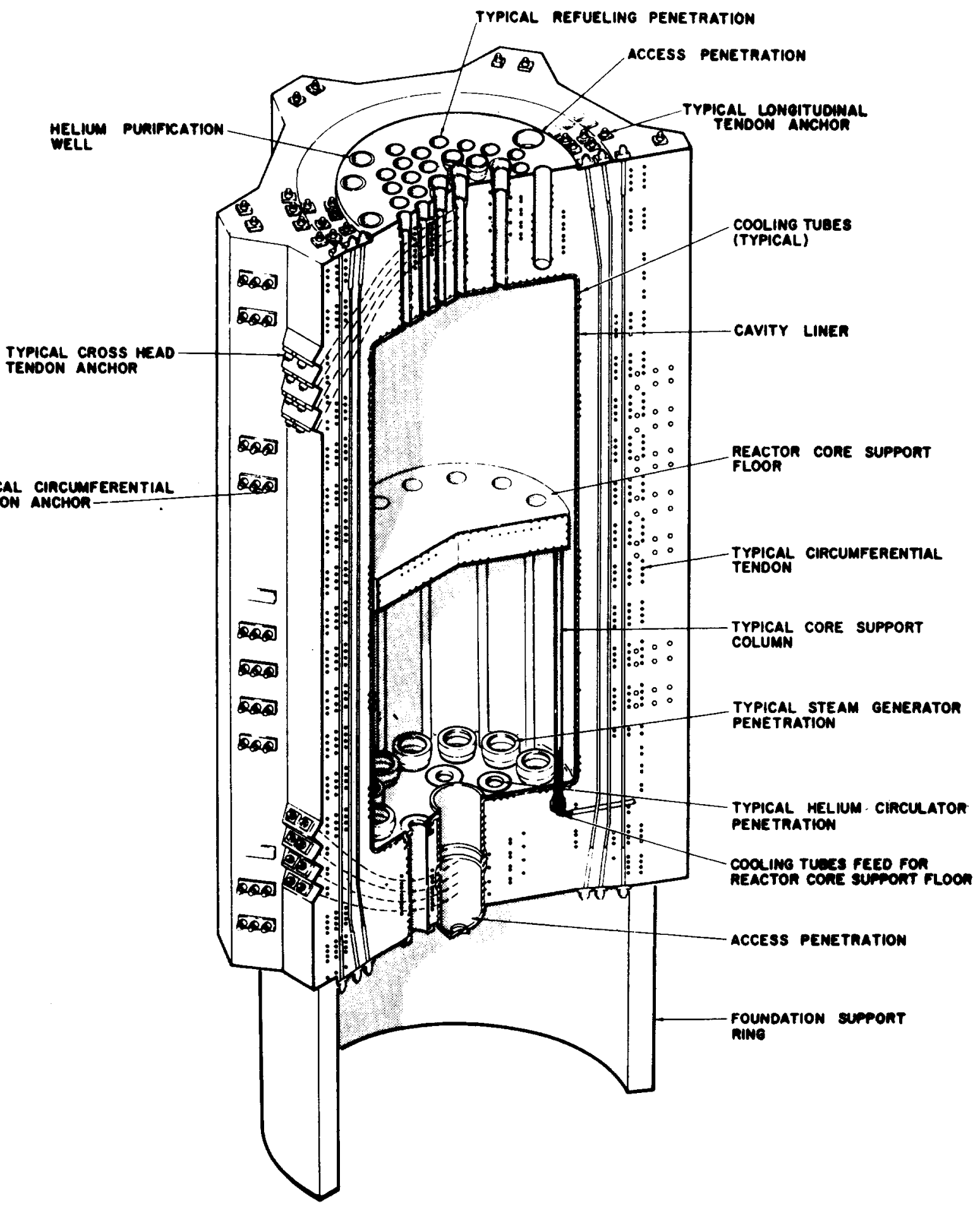


b)

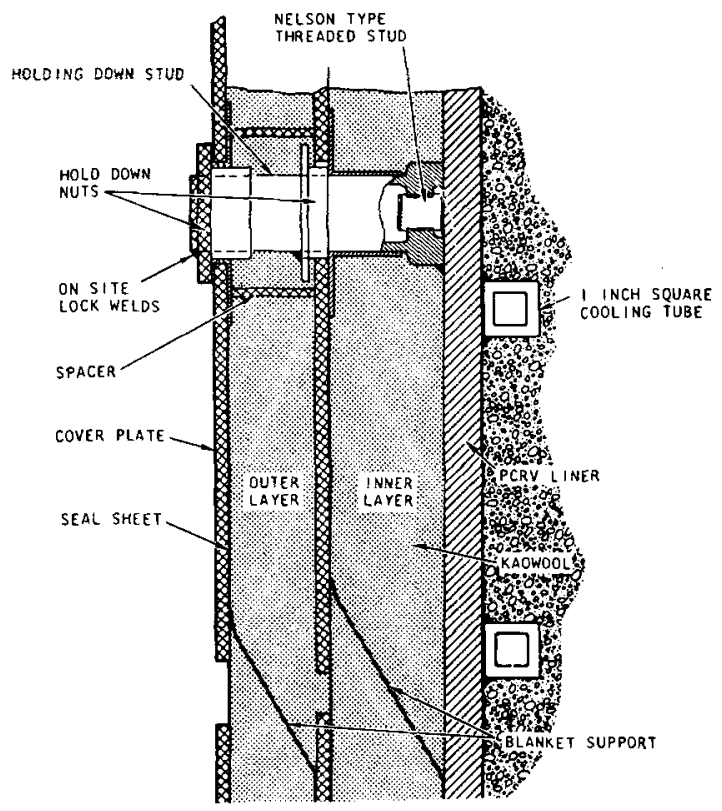

c)

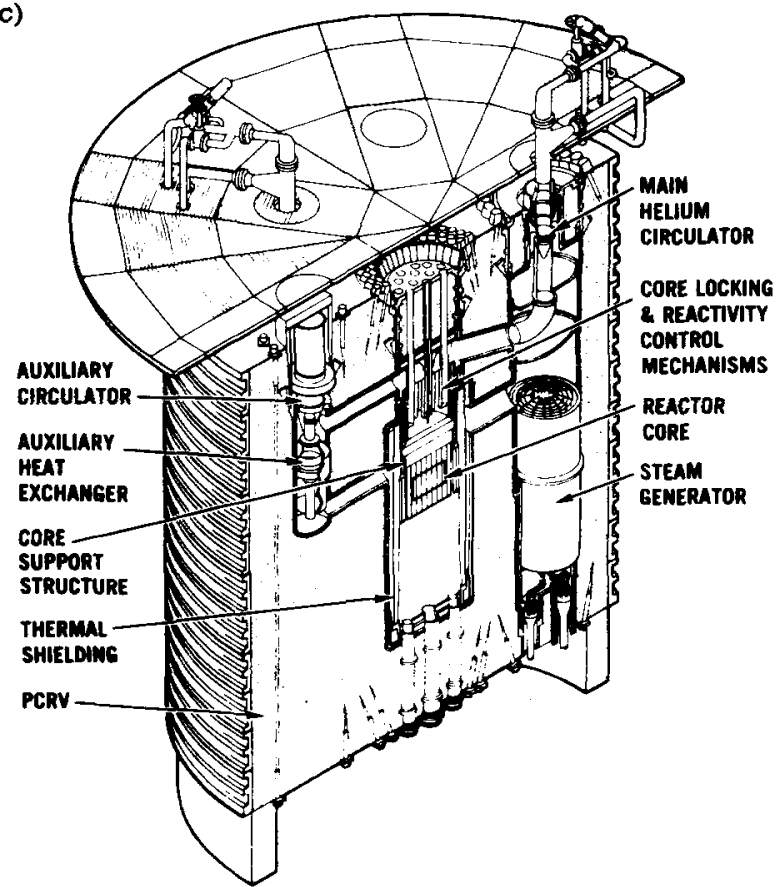

Fig. 1. Examples of single-cavity PCRVs (a) and multi-cavity PCRV (c), and example of an internal thermal barrier (b). (a, b) Fort St vrain Vessel, (c) Design of a gas-cooled fast reactor demonstration plant PCRV; after Olson et al. [18] (a, b) and Robinson et al. [19] (c). 
design and analysis. Emphasis is placed in this lecture on the developments made at Northwestern University and at Argonne National Laboratory. It is not possible to include in this lecture a systematic or exhaustive review of the subject. The literature on PCRVs and related topics has become vast and a number of recent outstanding state-of-the-art reviews by Naus [4,6,8-13] and others [7,14-16] may be consulted for that. Most of the past developments are covered in the SMiRT proceedings [17]. For reviews of various special aspects see refs. [18] and [19].

\section{Principal features, advantages and safety aspects}

The internal pressure in a PCRV is resisted primarily by its high-strength prestressing steel. Concrete in the vessel is reinforced by a large amount of mild steel reinforcement to allow it to resist local stress states, transmit tension and shear, distribute cracking, and assure a large energy absorption capability. Although the permeability of a PCRV wall (typically several meters thick) is virtually negligible, present practice relies for leak-tightness solely on a continuously welded steel liner anchored to the internal surface of the concrete by studs. According to the current state-of-the-art and existing codes $[20,21]$, the temperature of the concrete must be limited to $65^{\circ} \mathrm{C}$. This is ensured by a cooling system involving steel tubes welded to the liner and embedded in concrete, and by an insulation layer covering the internal surface of the liner. The liner also prevents leakage of radioactive fission products into the concrete wall, as well as leakage of vessel coolant into the reactor cavity. The concrete of the PCRV is normally sufficient to provide adequate radiation shielding. The prestressing system usually includes vertical tendons, tendons crossing the top and bottom slabs, and circumferential prestressing. The latter consisted in the earlier designs also of tendons, while recently a wirewinding system, developed in the UK, has been preferred.

The classical design of a PCRV involved a single large cavity containing both the reactor and the heat exchangers. Typical designs of a single-cavity and multi-cavity (poded) arrangement are shown in fig. 1 . Also shown is a typical thermal barrier. Due to difficulties in access to the heat exchangers, a multicavity design has been preferred recently. In this arrangement, the heat exchangers as well as the circulating pumps are directly accessible through large openings in the top slab of the vessel. However, single cavity vessels might be more economic for small PCRVs, and also might offer a more effective heat removal by natural gas circulation if the gas circulator pumps failed.

PCRVs have several important advantages in comparison with steel vessels.

(1) There is essentially no limit to the wall thickness, and, therefore, to the internal pressure and the size of the cavity. Increasing the wall thickness brings about no additional technical difficulties, while increasing the thickness of steel vessels beyond the current limits involves major obstacles (although they can be to some extent circumvented by using a multilayer steel wall with shrink fit). Thus, the unit cost of a PCRV decreases with its size, whereas that of a steel vessel increases.

(2) The load-bearing structure - the PCRV - provides at the same time radiation shielding. For a reactor with a steel vessel, a massive concrete wall serving only the purpose of radiation shielding must be erected outside the steel vessel.

(3) Most importantly, the PCRVs have several attractive safety features (fig. 2). These features are due to the following properties: (a) Stress redistribution and structural redundancy, inherent to the nature of the prestressing system. Since the prestressing tendons are independent, their simultaneous failure is extremely unlikely, virtually impossible. Should one of the tendons break, its tensile force is essentially uniformly redistributed over the remaining tendons, increasing their internal forces only very little (fig. 2a). By contrast, in a steel vessel, the appearance of a small failure, i.e., a small crack, causes large local stress concentrations at the crack front, which tend to cause further crack propagation. Although fracture mechanics has led to a safe design of reactor steel vessels, the self-limiting nonpropagation property of tendon failure makes the PCRVs still safer [22]. (b) Aside from the prestressing tendons, concrete has also favorable failure properties. The appearance of a crack in concrete does not generally cause sharp stress concentrations because, due to the composite aggregate nature of the material as well as the dense distribution of mild reinforcement, a continuous crack always has, at its front, a large zone of dispersed microcracks which blunt the stress concentrations (fig. 2b). Thus, concrete, and especially a densely reinforced concrete, is a material of very low sensitivity to flaws. (c) Due to the aforementioned property of distributed cracking and microcracking, as well as the stress-strain diagram for prestressing steel, a PCRV possesses a large amount of ductility, i.e., the deformation at failure is many times larger than the deformations 
under service loads (fig. 2c). The failure happens gradually, and a great amount of energy is absorbed in the process. The high energy absorption capability of a PCRV is particularly advantageous for explosive dynamic loads. (In detail, see ref. [22].) (d) The state of stress of tendons, the principal loadbearing components, can be checked at any time. If necessary, the stress can be adjusted, or the tendon replaced provided that ungrouted, greased, tendons are used, as is the US practice.

It must be admitted that PCRVs have also certain disadvantages.

(1) One obviously is, in contrast to steel vessels, the need to keep the material temperature under $65^{\circ} \mathrm{C}$ (further developments may, however, remove this limitation, as will be considered later).

(2) The need to produce several components inside a single cavity causes fabrication congestion, and increases costs.

(3) The requirement to consider a pressurized throughcrack is a disadvantage. Because of the much larger wall thickness compared to a steel vessel, the internal pressure in the crack has a much larger force resultant.

(4) A weak point of a PCRV are large penetrations and openings. They interfere with the prestressing system and require deflecting tendons around the penetration, or anchoring them at the penetration. This usually causes critical congestion of reinforcement and tendons.

\section{Some technological advances}

\subsection{Penetrations}

The design of large penetrations and openings has been intensely studied for a number of years $[6,7]$ and further developments are still needed. A particularly large opening is required in the top slab of a prestressed concrete guard vessel considered for a sodium-cooled fast breeder reactor. An arrangement of prestressing tendons that would permit a large opening without reducing the strength of the vessel has been studied at Argonne National Laboratory. Instead of deflecting the prestressing tendons around the opening, the opening was conceived as a heavy steel ring, essentially a steel structure embedded in the concrete of the top slab [23]; (see fig. 3). The ring was designed so as to be able to serve simultaneously for anchorage of tendons. The vertical tendons of the barrel section of the vessel were deflected toward the ring and anchored in it. Dynamic finite element analysis with cracking has shown that the opening designed in this manner causes no reduction of the load carrying ability, particularly the resistance of the vessels to a slug impact of the sodium mass onto the top slab of the vessel, expected in a postulated hypothetical core-disruptive accident. Designing large openings as steel structures embedded in concrete is probably the best means of avoiding reductions in the load carrying ability of PCRV.

\section{a. Redundancy}

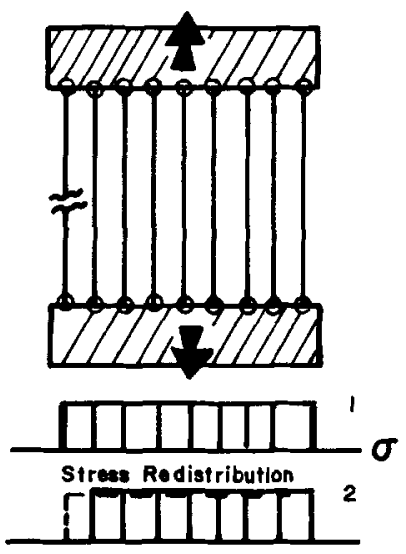

b. Insensitivity to Flaws

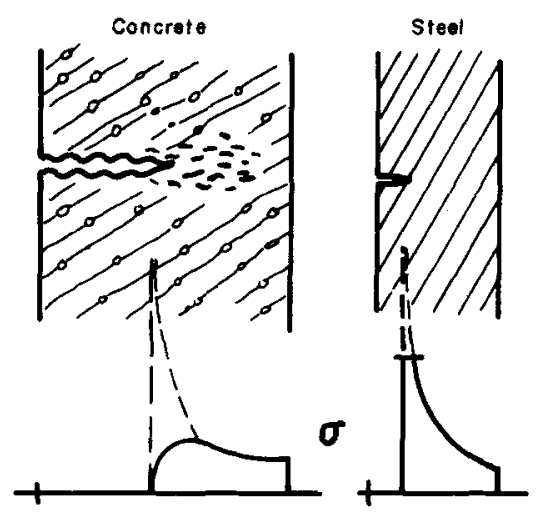

\section{c. Ductility}

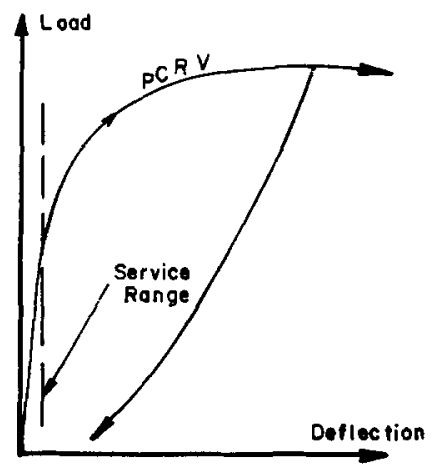

Fig. 2. Sketches illustrating chief advantages of prestressed concrete reactor vessels. 


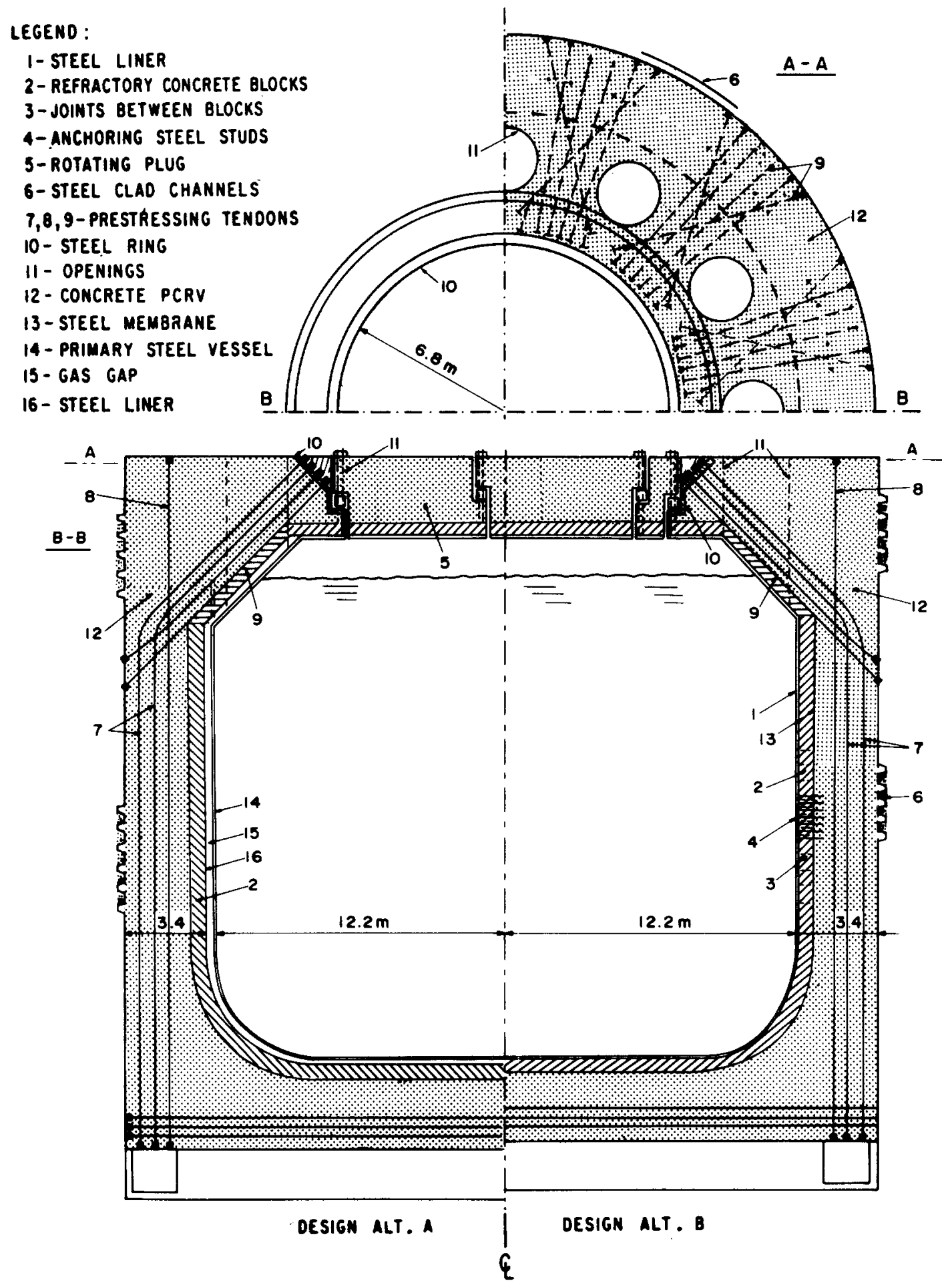

Fig. 3. Conceptual design of a PCRV as a guard vessel for an LMFBR, with refractory concrete, and with a top slab penetration formed by a heavy steel ring that serves for anchorage of tendons (after Bažant et al. [23]). 


\subsection{High temperature resistance}

Another area where technological improvements are possible and highly desirable is the design of concrete for high-temperature exposure as well as chemical attack by molten sodium or molten core. The limitation of $65^{\circ}$ for the temperature of concrete has been imposed chiefly because of incomplete knowledge of the material response and difficulties of analysis. It is well-known that normal (portland cement) concrete can be exposed to temperatures up to $400^{\circ} \mathrm{C}-600^{\circ} \mathrm{C}$ without experiencing any drastic reduction of strength. The fire resistance of concrete structures depends, of course, on this fact. However, to design a massive concrete wall for heating to such temperatures requires a reliable evaluation of the volume changes, pore pressures, moisture movements, deformation, cracking, and creep, and more research into the material behavior needs to be carried out before such designs can become a reality.

Due to the presence of a large amount of water in concrete, the boiling temperature of water $\left(100^{\circ} \mathrm{C}\right)$ is obviously a critical point at which substantial changes occur in a concrete structure. Subsequent heating up to about $400^{\circ} \mathrm{C}$ produces less significant changes in the structure. It is important to realize this fact with regard to certain postulated accidents which involve a sudden rapid heating of concrete well over $100^{\circ} \mathrm{C}$ [26-28]. The effect of such an accident would become more predictable if the concrete structure were already at a temperature over $100^{\circ} \mathrm{C}$ before the accident happens. The additional release of water due to further heating would then be far smaller, compared to a structure that is initially at $65^{\circ} \mathrm{C}$, the pore pressures generated would be much lower, the thermal expansions and thermal stresses would be also lower, and cracking would be more limited. Therefore, if certain hypothetical accidents that involve rapid heating of concrete to high temperatures are deemed to have a nonnegligible probability, it would be advantageous to design PCRVs that operate in service at temperatures slightly over $100^{\circ} \mathrm{C}$. One would thus trade a more predictable, safer response to hypothetical accidents for complications due operating the PCRV permanently at high temperatures.

This idea was developed as the hot-liner concept for
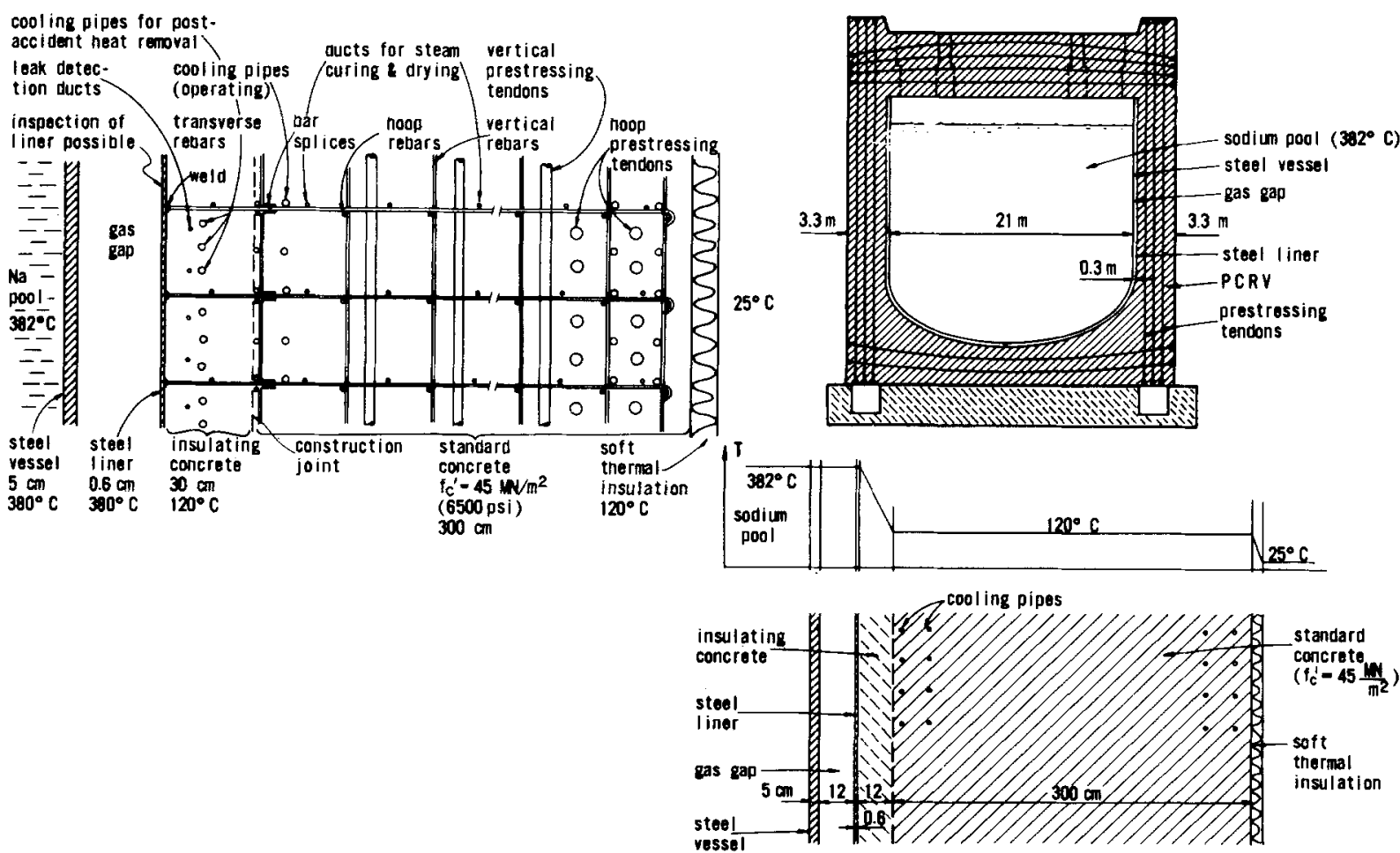

Fig. 4. Conceptual design of a dried-hot prestressed vessel as a guard vessel for an LMFBR (after Bažant and Fistedis [29]). 
gas-cooled reactors as well as light water reactors by Német et al. $[24,25]$. In these very interesting innovative designs, no particular provision was made for the escape of pore water from concrete due to heating. Even though the permeability of water in concrete above $100^{\circ} \mathrm{C}$ is two orders of magnitude higher than at room temperature, the large wall thickness prevents drying of the wall within a reasonably short time. Yet, driving water out of concrete, if it could be made without causing cracks, is desirable because uncracked dried concrete is stronger than saturated concrete (at any temperature). Also, its creep is smaller, volume changes are smaller and less predictable, the pore pressure build-up due to further heating in an accident is less, and, as far as the LMFBRs are concerned, the reactivity of dried concrete with sodium is diminished.

In recognition of these facts, a conceptual design of a hot-dried vessel was outlined in ref. [29]. Drying ducts of approximately $1 \mathrm{in}$. diameter would be provided in the concrete wall, with a spacing of about $12 \mathrm{~cm}$ (fig. 9). If air of $120^{\circ} \mathrm{C}$ temperature were circulated through these ducts, it would be possible, as calculations showed [29], to dry the PCRV wall within approximately one week. Certain provisions would have to be made to avoid producing cracks. The same ducts could later be used to keep the concrete of the PCRV permanently at the same temperature through the entire lifetime. It might be also possible to use initially the same ducts for steam curing, which is known to produce concrete of certain beneficial properties for high-temperatures.

In the case of an LMFBR (typified by the current designs in fig. 5 [30]), a particularly rapid heating of a concrete wall would occur if the primary steel vessel should break. If the concrete wall is provided with a steel liner that does not break, the spill of molten sodium contacts only the liner and has the sole effect of rapid heating of the concrete wall, possibly to several hundred degrees Celsius. The evaporable water present in concrete does not have enough time to escape through

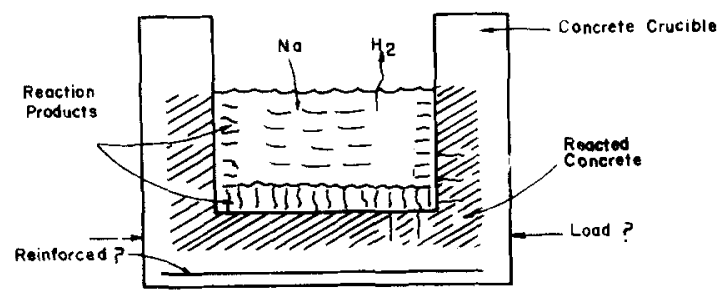

Fig. 5. Illustration of testing sodium-concrete interaction in a crucible. the concrete wall, due to its thickness, and, in contrast to the effects of fire on normal structures, escape of water through the heated face is prevented by the liner. Consequently, a substantial pore pressure build-up and large volume changes of concrete may be expected. This might in turn endanger the leak-tightness of the liner. It might well be that such a catastrophic failure is impossible, however, a fully realistic analysis based on a sufficient knowledge of material properties has not yet been carried out.

\subsection{Attack of molten sodium on core melt}

If we admit the possibility, as remote as it may be, of contact between liquid molten sodium and concrete, one needs to study its consequences. Many investigations have been recently devoted to this problem [33-44]. Sodium reacts not only with water, which is a highly exothermic reaction and generates much hydrogen gas, but also with silica $\left(\mathrm{SiO}_{2}\right)$, which is present in abundance in portland cement. The basic reactions are

$2 \mathrm{Na}+\mathrm{H}_{2} \mathrm{O} \rightarrow \mathrm{Na}_{2} \mathrm{O}+\mathrm{H}_{2} ;$
$4 \mathrm{Na}+3 \mathrm{SiO}_{2} \rightarrow 3 \mathrm{Na}_{2} \mathrm{SiO}_{3}+\mathrm{Si}$.

Aggregates containing significant amounts of silica should, therefore, be avoided if sodium exposure is of concern. Generation of free hydrogen is a highly undesirable aspect which cannot be avoided unless different types of cement (certain refractory cements) are used.

Molten sodium was dumped in concrete crucibles (fig. 5) and progress of the reaction was observed. The reaction with sodium, also called sodium fire, would be self-limiting if the slag forming the reaction product would stay in place, preventing further access of molten sodium to unreacted concrete. The slag tends to be carried away when a vertical wall of concrete is attacked by sodium, which explains why the sodium reaction has been observed in experiments to be stronger, and the damage deeper, in vertical walls than in horizontal walls. The depth of penetration of sodium considerably varied from experiment to experiment, ranging from 1 $\mathrm{cm}$ to many inches. Mostly, however, the reaction products arrested the reaction before a complete failure of the concrete crucible, but sometimes such a failure did occur.

The rate and extent of the reaction depends on many factors: the type of concrete and its aggregate, water content (dried concrete obviously reacts less than saturated concrete, unless highly cracked), the degree of prior cracking, if any, the presence of compressive stresses (prestress), the degree of confinement by rein- 


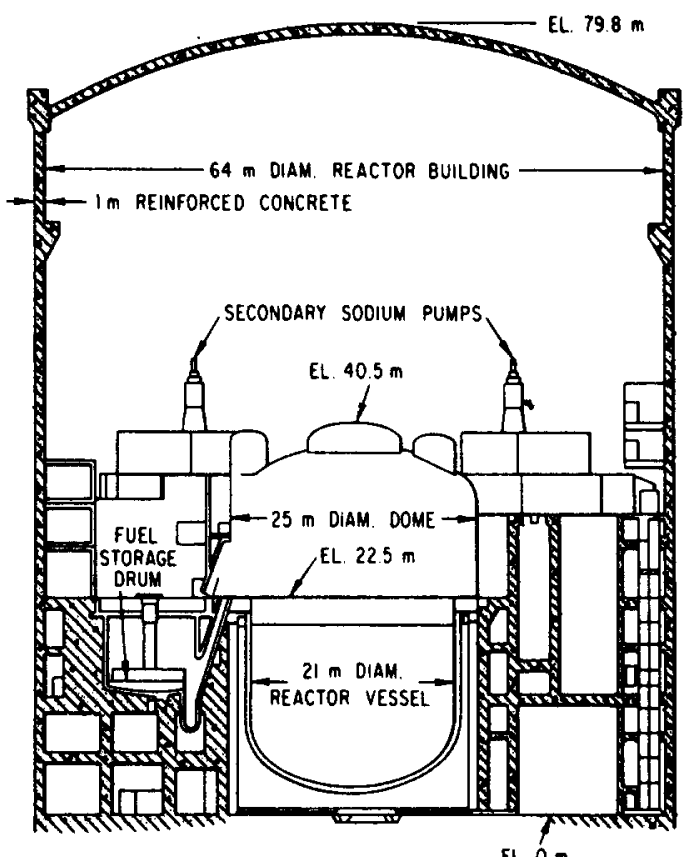

EL $0 \mathrm{~m}$

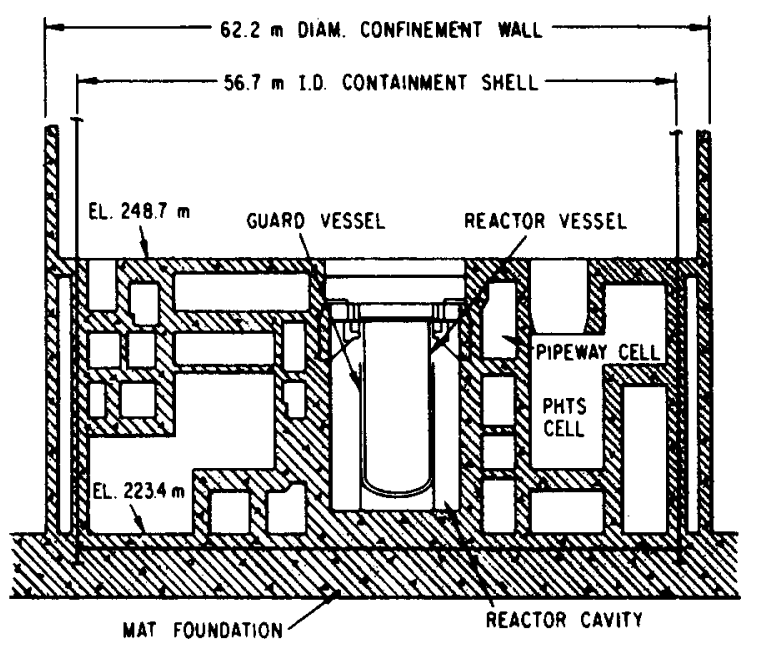

Fig. 6. Examples of concrete structures used in current state-of-the-art sodium cooled breeder reactors; (left) Superphénix, France, (right) Clinch River Breeder Reactor Design, USA (after Seidensticker et al., [30]).

forcement and by the rest of the concrete structure, wall thickness, hydrodynamics of the sodium pool, etc. Possibly reinforcement, confinement and compressive stresses might be means of controlling the depth of damage. The objective is to prevent formation of large cracks permitting access of sodium to unreacted concrete behind the layer of reaction products. However, transverse ties may also have a negative effect due to increasing the conduction of heat into concrete. Especially damaging is spallation, producing chunks of concrete that can float away. Performance of the concrete wall might also be improved by using fiber reinforcement, which can reduce the crack width and increase the ductility, thus limiting spallation.

The build-up of pressure of pore water is no doubt also of importance, and its depends not only on the water content and reaction heat, but also on the thickness of the concrete wall which determines the rate of heat transfer by conduction. A build-up of high pressure may cause, together with high thermal compressive stress parallel to the wall, explosive spalling of the concrete wall, similarly as observed in fire tests. The presence of a steel liner, even if punctured, has no doubt a great limiting effect on the reaction. The chief question here is whether the liner would essentially stay in place or would be further torn up by the continuing reaction. To sum up, it now appears unlikely that a simple "rule of thumb" could be found. Determining the consequences of a sodium spill would probably require analysis of the kinetics of the chemical reaction, coupled with the analysis of stress, deformation, cracking, heat transfer, and water transfer in the concrete wall. To be able to do that, further research into the requisite material properties is needed.

Nevertheless, various measures significantly limiting the sodium reaction can be identified now. Aside from the aforementioned measures of reinforcement, confinement and prestress, use of the liner, advantage of dried concrete, etc., one can achieve a greatly reduced or zero reactivity with sodium through the use of certain refractory concretes. Refractory concretes, on the other hand, would greatly improve the performance of the concrete vessel if heating above $400^{\circ} \mathrm{C}$ is considered, even if no contact with sodium takes place.

In analyzing certain postulated hypothetical coredisruptive accidents, the question arose as to what would be the response of a concrete wall when heated to temperatures of molten steel, or even molten reactor core (containing molten uranium oxide), or when the concrete is directly contacted by these melts [31,32]. 
Various experiments with concrete crucibles have been conducted and reaction rates observed [33]. The slag formed by the reaction again has a limiting tendency, and the question of heat removal from the melt is obviously of great importance, too. As for influencing factors, they are similar to those mentioned above for the sodium reaction. Again, a detailed mathematical modeling based on material properties and reaction kinetics would be required to fully answer all designer's questions. In these types of exposure, refractory concretes would be of an even greater benefit.

\subsection{Refractory and special concrete}

The current state of knowledge of the properties of various refractory concretes has been surveyed in detail in a recent cooperative project between Northwestern University and Portland Cement Association, funded by EPRI; see ref. [33] listing 350 references. These reports survey material composition, physical and chemical changes (drying and dehydration, porosity, internal surface area, chemical changes in aggregates, etc.), thermal expansion and shrinkage, pore pressure, strength, ductility, stress-strain relations, elastic properties, creep, heat capacity, heat transfer, water transfer, explosive thermal spalling, reinforcing and prestressing steel, and sodium-concrete interaction, for various refractory concretes as well as normal portland cement concrete. Evaluation of these concretes for LFMBR applications is also made.

High alumina cement concretes would be useful, but only if prefired in order to form a ceramic bond. The firing must be done at a temperature above $1000^{\circ} \mathrm{C}$, which can hardly be carried out on the full vessel. Instead, one must contemplate the use of blocks of no more than several feet in size, fired separately. Another reason against using these concretes in mass is the large hydration heat. If prefired, these concretes maintain high strength up to roughly $1000^{\circ} \mathrm{C}$, have very small thermal expansion and low creep rate. The lowest creep rate is obtained with chrome ore aggregate, however, this aggregate reacts with sodium. The best properties, including the least reactivity with sodium, would be obtained with corundum aggregate. Tabular alumina aggregates and crushed chamotte (highest density fire brick) may be expected to also perform well.

Nonhydraulic cement concretes, such as phosphatebonded, magnesia-bonded and waterglass-bonded concretes are of interest since they do not need water for their chemical hardening and, therefore, contain no chemically bound water (high alumina cement concretes do not either, but only if fired). However, water must still be used for mixing in these concretes; it is driven out by moderate heating, which is anyhow required to make these concretes harden (their initial "strength" is very small or zero). Good performance would be obtained with phosphate-bonded concrete involving, as the best choice, corundum aggregate, or possibly crushed chamotte, or with magnesia-bonded concrete involving chrome ore aggregate if no sodium exposure is expected. Waterglass concretes have a very high permeability. Generally, these nonhydraulic cement concretes appear suitable for use as a thin layer, e.g., between blocks [34]. Finally, when temperatures are limited to about $600^{\circ}$ to $700^{\circ} \mathrm{C}$ and no sodium exposure is expected, acceptable service may be obtained from normal, portland cement concretes with refractory aggregates, e.g., crushed chamotte [33].

For structural, load-bearing service at temperatures up to $400^{\circ} \mathrm{C}$, the use of portland cement concretes appears preferable [33]. No refractory concretes or brick system seems to offer any definite advantage in this temperature range. As already mentioned, keeping the concrete hot during service and depriving it of its evaporable water (without causing cracks) would give improved behavior in case of accidents.

For molten sodium containment up to $880^{\circ} \mathrm{C}$, other materials are preferable. High-alumina cement concretes would probably perform better because they contain no large amounts of silica. Dense refractory brick linings will give optimum performance, owing to their extremely low porosity, as compared to concretes. This is confirmed by the fact that such linings are used in vessels for sodium production, and is verified by laboratory tests [33]. Waterglass concrete may have an almost negligible reactivity with liquid sodium, but its use is questionable because of its high porosity.

The choice of aggregate is very important for sodium resistance. As a general rule, aggregates containing silica or chrome ore should be avoided in this regard. Best would probably be tabular alumina or corundum. Zirconia, silicon carbide, and magnesia, as well as limestone, would also be acceptable.

For core melt isolation (above $870^{\circ} \mathrm{C}$ ), zero or negligible damage can be obtained only with dense refractory brick linings and nonhydraulic concretes, especially the phosphate or magnesia concretes. These materials have been proven in industry for being able to contain molten steel and other metals. They include: high-density alumina brick, high-density magnesia brick, and zirconia brick. For melts no hotter than $1100^{\circ} \mathrm{C}$, high-alumina cement concrete with high quality refractory aggregates (corundum or tubular alumina), if previously fired, may also serve without significant damage. 


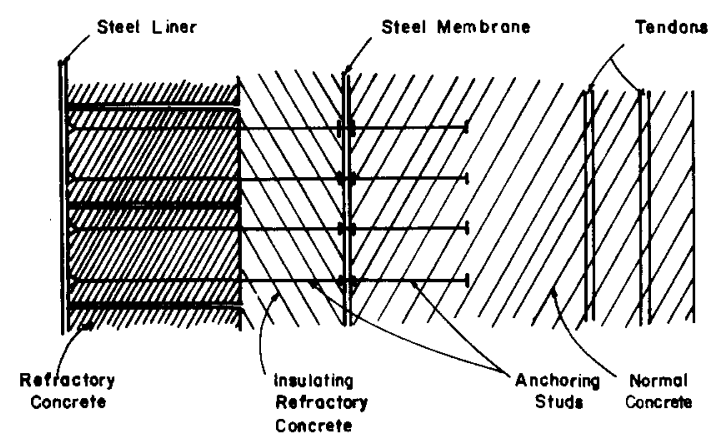

Fig. 7. Conceptual design of a wall of PCRVs with a layer of refractory concrete (after Bažant et al. [34]).

As pointed out before, normal portland cement concrete might as well prove acceptable if the melt solidifies before the damage advances all the way through the wall.

A particular design of a concrete wall of a secondary guard vessel for LMFBR has been considered in ref. [34] (fig. 7). The wall, protected either by a steel liner (or directly by the sodium-containing steel vessel) which is anchored into the wall by welded studs, has a layer of large prefired refractory concrete blocks (e.g., high alumina cement concrete with crushed fire brick aggregate) followed by a layer of insulating refractory concrete. Below it there is a steel membrane, a layer of insulating normal concrete and then normal concrete of the PCRV. The studs anchoring the liner are extended to pass through the steel membrane and are anchored into the normal PCRV. The refractory concrete blocks are either dry-jointed, or better, jointed with a layer of nonhydraulic cement mortar.

\section{Analysis of response}

\subsection{Progressive cracking}

As is clear from the preceding considerations, analysis of cracking and fracture is important for predicting structural performance. So it is for predicting the effects of internal overpressure or dynamic loads. Until recently, it has been thought that the analysis of cracking can be adequately carried out by the smeared cracking model, in which a system of parallel cracks is assumed to be continuously and uniformly distributed over the area of the finite element (or over an area surrounding an integration point within a finite element), and the tensile stress is suddenly reduced to zero when a certain strength criterion in terms of stresses (or strains) becomes satisfied. This concept, introduced by Rashid [45], is however only partly representative of the reality, and without application of fracture energy concepts it leads to results that are unobjective, as far as their dependence on the choice of the mesh is concerned, and are in disagreement with fracture tests of concrete [46-51].

To explain the deficiencies of the cracking model presently used in large finite element codes for the analysis of PCRVs, let us apply this model to the simple case of a rectangular panel subjected to uniform tension at top and bottom sides (fig. 8). We assume that initially two elements in the center of the panel are cracked and that a horizontal crack band of a single-element width propagates along the symmetry line of the panel. We want to calculate the multiplier $\alpha$ of given design load $p$ for which the crack band propagates further. We carry out the finite element computations for three different meshes; mesh $\mathrm{B}$ as shown in fig. 8, mesh $\mathrm{A}$ with elements twice as large, and mesh $\mathrm{C}$ with elements half as large.

If the strength criterion is used, i.e., if it is assumed that the maximum principal tensile stress drops suddenly to zero when the strength limit $f_{t}^{\prime}$ is reached, the results plotted by the solid curves in fig. $8 \mathrm{~b}$ are obtained. These curves represent the load multiplier causing further crack band propagation as a function of crack band length $a$. As expected, the longer the crack band length, the smaller the load multiplier needed for further propagation. One is, however, immediately struck by the huge differences among the results for the three meshes A, B, C. Moreover, if the mesh were further refined, the load multiplier $\alpha$ would converge to zero for any crack length $a$, i.e., crack band propagation would be obtained for an arbitrarily small load if a sufficiently fine mesh were used. Thus, the strength criterion yields unobjective results, depending on the analyst's subjective choice of the mesh. The solution converges, as it must according to well-known theorems, however, it converges to a physically incorrect solution.

Intuitively, one may attribute this finding to the fact that the crack band front is of a single-element width. Consequently, if the element size gets smaller, then the stress concentration causes a higher tensile stress in the element just ahead of the crack front, and this stress can be made as large as desired by choosing sufficiently fine elements.

One might, therefore, ask whether a remedy could not be obtained by enforcing in the finite element code a multiple element width at the crack band front. This would be, however, incorrect (unless the model were 

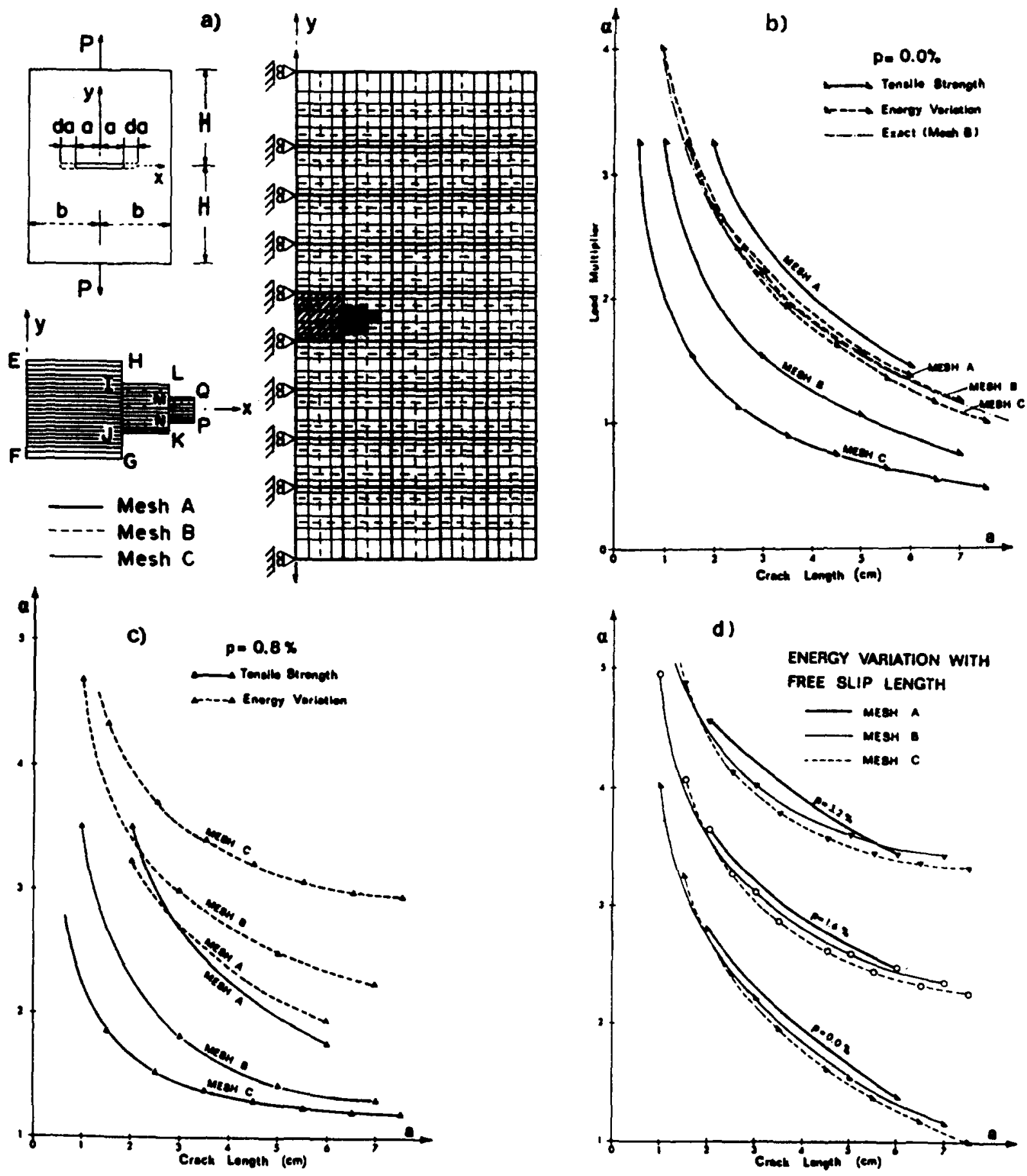

Fig. 8. Example of finite element cracking analysis of a rectangular panel subjected to tension and calculated according to the strength criterion and the energy criterion; (a) finite element meshes, (b) unreinforced panel, (c) reinforced, without bond slip, (d) reinforced, with bond slip (after Bažant and Cedolin [48]). 
modified as described later). For one thing, if the crack front is considered to be, e.g., three elements wide, then one can show that by a deformation increment of strain-localization type, in which the strain in two frontal elements decreases and in one increases, energy is released by the structure (with loads and boundary supports being fixed). This is an unstable situation, which cannot exist as a static case. For another thing, a multiple-element crack-front width cannot be obtained if the loading step is made sufficiently small since one element then cracks before the other one does, and thereby it relieves the tensile stress in the other element on the side, which itself cannot be made to crack. Even if the stresses in two adjacent frontal elements were exactly the same, this would not be a realistic assumption since the random scatter in material properties always causes, even then, one element to crack before the other one does.

We can illuminate the problem by considering the energy $G_{f}$ consumed by the formation of fracture. If we adopt the idea of a blunt crack band, the energy consumed by a unit extension of crack-band length may be expressed as

$$
G_{\mathrm{f}}=A w_{\mathrm{c}}, \quad A=\frac{f_{\mathrm{i}}^{\prime 2}}{2}\left(\frac{1}{E}+\frac{1}{-E_{\mathrm{t}}}\right)
$$

in which $w_{\mathrm{c}}$ is the width of the crack band front (fig. 9); $A$ is the work dissipated per unit volume of the crack

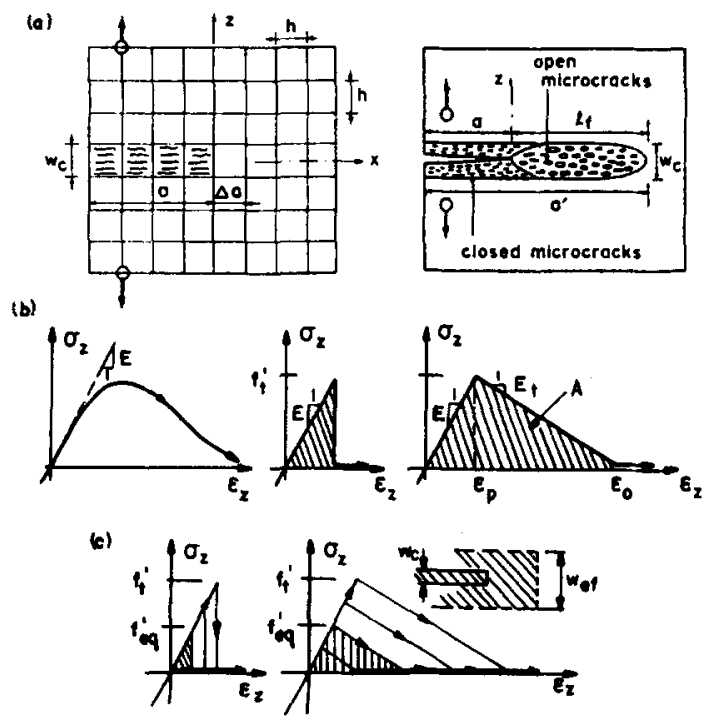

Fig. 9. Finite element smeared crack modeling (a), tensile stress-strain diagrams used (b), adjustment required when element size changes (c). band, equal to the area under the complete tensile uniaxial stress-strain curve (fig. 9b); $f_{\mathrm{t}}^{\prime}=$ direct tensile strength, $E=$ elastic Young's modulus, and $E_{\mathrm{t}}=$ mean strain-softening modulus (negative) in uniaxial tension. In writing eq. (1), we simplify the tensile stress-strain diagram to a bilinear form. For its downward segment we consider in fig. 8 the extreme case of a vertical stress drop. It is, however, well-known from various experiments on small concrete specimens in very stiff tensile testing machines that, in reality, the softening modulus $E_{\mathrm{t}}$ is finite, i.e., the material does exhibit (if stable) a gradual strain-softening (decrease of stress at increasing strain); see test data in ref. [52-56]. The case of a vertical (sudden) stress drop is the limiting case for $\left|E_{\mathrm{t}}\right| \rightarrow \infty$.

Recently, it has been found [57-59] that if the width of the crack band front, $w_{c}$, is considered to be a material constant, then the blunt crack band model with strain-softening is capable of closely representing all essential fracture test results for concrete (as well as rocks), in particular the deviations of these results from the linear elastic fracture mechanics, which were, at first, thought to disprove the applicability of fracture mechanics to concrete. In the course of these studies, it has been found that if the blunt crack band theory should represent not only the fracture test data but also the measured tensile stress-strain diagrams with strainsoftening [52-56] then the width of the crack band front $w_{\mathrm{c}}$ must be considered to be a material property. Empirically, it is found that $w_{\mathrm{c}}=n d_{\mathrm{a}}$ where $d_{\mathrm{a}}$ is the maximum size of aggregate and $n \approx 3$.

Furthermore, due to the small slope of the strainsoftening diagram, the fracture process zone, defined as the zone ahead of the fracture front in which the material undergoes strain-softening, is very long and can extend up to 12-20 aggregate sizes. The large size of the fracture process zone in concrete is independently confirmed by microscopic observations as well as deductions from other measurements [56,60-62], and is evidently a consequence of the heterogeneity of the material. As a consequence of this, the material cannot be treated as a continuum on scales that are not sufficiently large compared to the aggregate size. The continuum model that is implied in analysis is a macroscopic smoothed continuum, in which the stress and strain should be interpreted as the averages of the actual (microscopic) stresses and strains taken over a certain representative volume sufficiently large compared to the aggregate size. For practical analysis, the concept of a statistically heterogeneous continuum seems too complicated, and the crack band theory should be regarded merely as a convenient substitute. 
Consider now, as we did in our example, that the finite element size $h$ (in a square mesh) is not made equal to $w_{\mathrm{c}}=3 d_{\mathrm{a}}$ but is different. Then, the energy that is consumed per unit extension of the crack band is $G_{\mathrm{c}}=A h$. Here $A$ remains constant if the element size $h$ is varied,and so we see that the larger the element size, the larger the energy consumed by fracture. For an infinitely small element size, the energy consumed by fracture becomes infinitely small, which is evidently a physical nonsense. Analysis of fracture tests confirms that the fracture energy of concrete is a constant, and this can be ensured only if the finite element size equals $3 d_{a}$, provided that the correct tensile strength limit $f_{\mathrm{t}}^{\prime}$ is considered.

Finite elements of this size would normally be too small for the analysis of PCRVs, and the analysis needs to be carried out with larger finite elements. It has been numerically demonstrated that a larger finite element size can be considered if one modifies the strength limit $f_{\mathrm{t}}^{\prime}$, replacing it with an equivalent strength $f_{\mathrm{eq}}^{\prime}$, such that the same fracture energy $G_{\mathrm{f}}$ be dissipated during crack band propagation. Solving eq. (1) for $f_{t}^{\prime}$, and replacing $w_{\mathrm{c}}$ with element size $h$ and $f_{\mathrm{t}}^{\prime}$ with $f_{\mathrm{eq}}^{\prime}$, we obtain

$f_{\text {eq }}^{\prime}=C_{0} / \sqrt{h}$,

in which $h$ is the element size and $C_{0}$ is a certain constant. Thus, we see that the strength limit must be decreased if the finite element size is increased. Only in this manner one can ensure that the energy consumed by crack band propagation is independent of the analyst's subjective choice, i.e., the analysis is objective.

Alternatively, if a vertical stress drop is considered, one may specify no tensile strength limit and may instead directly calculate the change of potential energy $\Delta U$ of the structure as the crack band is extended by the length of one element, $\Delta a=h$. The value of $\Delta U$ may be calculated either from the difference in the potential energies of the structure before and after the crack band extension (provided the rest of the structure behaves linearly), or from the work of the nodal forces acting upon the finite element that undergoes cracking [46-51]. Still another possibility for calculating $\Delta U$ is the use of the $J$-integral $[63,64]$. The rate of energy release corresponding to the crack length $a+\Delta a / 2$ (fig. 8a) may then be approximated as $U^{\prime}=-\Delta U / \Delta a$. In the finite element calculation one needs to test the crack band extension into the next element. If the value of $U^{\prime}$ is less than $G_{f}$, the crack band does not extend, and if this is not so, it does extend.

Let us now return to our example of a center-cracked rectangular panel (fig. 8a). If the finite element analysis for sudden cracking with a vertical stress drop is carried out on the basis of the energy criterion, meshes $\mathrm{A}, \mathrm{B}, \mathrm{C}$ from fig. $8 \mathrm{a}$ yield the dashed curves in fig. $8 \mathrm{~b}$. We see that the results are consistent, i.e., objective (independent of analyst's choice), except for a small numerical error which converges to zero with mesh refinement $[46,48]$. A similar agreement is found when the equivalent strength criterion is used [51].

It has been demonstrated [58] that, with a fixed tensile strength limit, significant discrepancies among the results for meshes $\mathrm{A}, \mathrm{B}$, and $\mathrm{C}$ are obtained also in the case of strain-softening with a finite slope $E_{\mathrm{t}}$. Here the use of element sizes different from $3 d_{\mathrm{a}}$ may be allowed if again the value of the peak stress $f_{t}^{\prime}$ is adjusted to the equivalent strength $f_{\text {eq }}^{\prime}$ (see fig. 8c). In fact, the sensitivity of the results to the chosen mesh size, and the strain-softening instabilities, are a salient feature of all strain-softening behavior, even that for compression of shear loadings.

In deriving eq. (2), we assumed that the fracture energy $G_{\mathrm{f}}$ is a constant. This might be contested on the basis of the measurements of the so-called $R$-curves (resistance curves), which represent the fracture energy $G_{\mathrm{c}}$ as a function of the crack extension $a$ from the body surface or a notch. For approximate analysis, the $R$ curve, i.e., the curve $G_{\mathrm{c}}(a)$, may be considered as a material property in conjunction with linear elastic fracture analysis. However, the variability of $G_{\mathrm{c}}$ is in no contradiction with the constancy of $G_{\mathrm{f}}$ ( $G_{\mathrm{c}}$ is not the same as the fracture energy $G_{\mathrm{f}}$ for the crack band theory; it is a fracture energy evaluated by methods of linear fracture mechanics rather than by means of the crack band model). That no contradiction exists is proven by the fact that realistic $R$-curves, as measured, may be calculated from the crack band theory with constant $G_{\mathrm{f}}$. The reason for obtaining variable $G_{\mathrm{c}}$ is that, when strain-softening is included, the fracture process zone implied in the finite element calculation becomes larger for a longer crack extension, so that a larger energy is being consumed per unit crack extension. The fact that in the crack band model the $R$-curves are automatically implied and the fracture energy $G_{\mathrm{f}}$, representing essentially the limiting value of the $R$-curve, may be considered as constant, is an advantage of this approach.

When the cross section is very large compared to the aggregate size, one needs to use finite elements that are much larger than $w_{\mathrm{c}}=3 d_{\mathrm{a}}$. In that case, it becomes immaterial whether the stress-strain diagram has a finite strain-softening slope or a vertical stress drop, and the only important property is the energy dissipated by fracture. For such very large structures (definitely for 
gravity dams, and possibly for large PCRVs) one may then carry out the analysis with a vertical stress drop and a strength limit $f_{\text {eq }}^{\prime}$ that is much smaller than $f_{t}^{\prime}$. Due to the vertical stress drop, the fracture process zone is relatively small, which means that the results should be similar to those of linear elastic fracture mechanics. This is indeed confirmed by finite element results [46-48]. For example, in the case of the center-cracked rectangular panel the results of the finite element analysis with a vertical stress drop and energy criterion differ from the exact solution of linear elastic fracture mechanics merely by one or two per cent, and are as close as those obtained by fracture analysis with a sharp inter-element crack, based on the calculation of energy release [48]. Thus, the crack band theory may be also used to obtain approximate linear elastic fracture solutions if a vertical stress drop is considered and if the mesh is sufficiently fine (about fifteen elements across the cross section).

While the principles of cracking analysis of concrete have now become clarified, much further work is needed for the implementation of this or some other similar approach in large finite element codes. Various investigations are being carried out for this purpose at Northwestern University, Argonne National Laboratory, Politecnico di Milano, and other institutions. The questions under investigation concern primarily:

(1) criteria for identifying the finite element adjacent to the frontal cracked element to which the cracking would further spread (the problem of crack band direction);

(2) representation of fractures of any direction as a zig-zag crack band through a square finite element mesh [99];

(3) the effect of reinforcement, particularly the steel ratio and bar direction, along with the effect of bond slip;

(4) effects of a multitaxial state of stress at the crack front on the tensile strength limit and the strain-softening behavior (e.g., the dependence of the strength limit on compressive normal stresses parallel to the crack planes);

(5) the rate effect on fracture, or the effect of creep, in which case the energy dissipation due to creep within the fracture process zone must be separated from the energy dissipation due to crack formation;

(6) determination of the crack front width in the presence of heavy transverse reinforcement, which may cause the crack front to be much wider than $w_{\mathrm{c}}$.

Although none of the foregoing problems have yet been resolved to complete satisfaction, various advances have been made. For example, the concept of equivalent strength has been extended to the case where densely spaced parallel reinforcing bars are crossing the crack band near its front. It has been shown $[48,50]$ that the expression for the equivalent strength must be modified as follows

$f_{\mathrm{eq}}^{\prime}=\frac{C_{0}}{\sqrt{h}}\left(1+c_{1} n \frac{p}{L_{\mathrm{s}}^{*}} \cos \alpha\right)$

in which $p=$ steel ratio, $\alpha=$ angle of bar direction with the crack plane, $n=$ ratio of Young's elastic moduli of steel and concrete, $c_{1}=$ empirical constant, and $L_{\mathrm{s}}^{*}=$ equivalent free bond slip length [48]. The value of $L_{s}^{*}$ may be approximately estimated from the ultimate bond force, the bar cross section, and the steel stress at the crack band crossing [49]. It is also of interest to note that, without consideration of bond slip, finite element analysis of the cracking of net-reinforced structures may lead to paradoxical results, which are unobjective with regard to analyst's choice of the element size [49].

Some structural engineers felt that the aspects of fracture energy and localization of cracking at the fracture front were important only for plain concrete and could be neglected for reinforced concrete. However, this is definitely not so, in general. This may be instructively demonstrated again with the help of the centercracked rectangular panel, reinforced by a regular net of bars in the vertical and horizontal directions. When the analysis based on a fixed tensile strength of concrete with a sudden stress drop is carried out for such a panel, the results shown as the solid curves in fig. 8c are obtained for the steel ratio $0.8 \%$ in each direction. The discrepancies among the results for meshes $\mathrm{A}, \mathrm{B}$ and $\mathrm{C}$ are again huge. They are also very large for the steel ratio, 3.6\% in each direction [49]. It is, therefore, necessary, even for this reinforced panel, to use an energy criterion.

However, the energy criterion itself is inadequate if the bond slip is neglected, in which case one obtains, for the three meshes, the dashed curves in fig. 8c. Only when the bond slip length, as mentioned before, is taken into account in the finite element analysis, the results for the three meshes become consistent for any steel ratio; see fig. 8d [49]. Thus, it is clear that one needs to worry about energy fracture criteria even for such heavily reinforced structures as the PCRV.

\subsection{Structural size effect due to cracking}

One important purpose of fracture mechanics is the size effect. When strength criteria, yield criteria, or failure envelopes in the stress or strain space are used in conjunction with elastic, plastic, or elastic-plastic anal- 

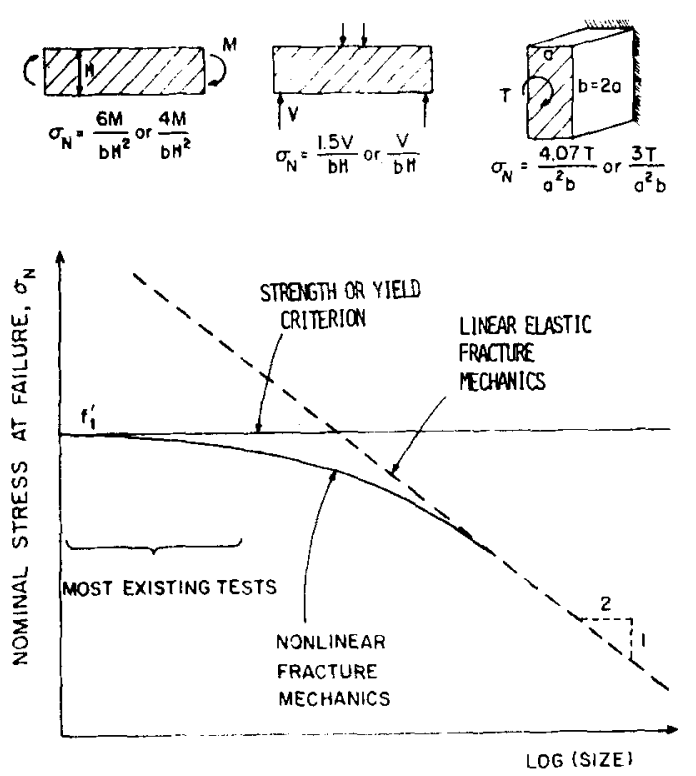

Fig. 10. Size effect for geometrically similar structures and examples of formulas used in strength criterion.

ysis, the nominal stress at failure, defined as the failure load or load parameter at failure divided by the characteristic dimension $d$ and thickness $b$, is constant when geometrically similar specimens or structures are compared. This is not so in fracture mechanics. In linear elastic fracture mechanics, the nominal stress at failure, $\sigma_{N}$, is not constant but varies inversely as $\sqrt{d}$. In the plot of $\log \sigma_{N}$ versus $\log d$, this translates into a straight line of downward slope $-\frac{1}{2}$, whereas the strength criterion corresponds to a horizontal straight line (fig. 10).

The size effect corresponding to the blunt crack band theory may be determined on the basis of the following hypothesis: The energy release $W$ caused by the formation of a crack band depends on

(1) length $a$ of the crack band, and on

(2) cracked area $A_{\mathrm{c}}$, which equals $n d_{a} a$.

Parameters $a$ and $A_{\mathrm{c}}$ are not nondimensional, but it must be possible to express the solution in terms of a nondimensionalized form of these parameters, which is $\alpha_{1}=a / d$, and $\alpha_{2}=n d_{a} a / d^{2}$.

Consider now geometrically similar specimens or structures. In that case, $W$ is a function of $\alpha_{1}, \alpha_{2}$, and further parameters $\xi_{i}$ characterizing the shape of the structure; furthermore, $W$ is proportional to volume $b d^{2}$ of the structure and to the characteristic energy density $\sigma_{\mathrm{N}}^{2} / 2 E_{\mathrm{c}}$ in which $\sigma_{\mathrm{N}}=P / b d=$ nominal stress at failure, $P=$ failure load, and $d=$ characteristic dimension of the structure. Consequently,
$W=\frac{P^{2}}{d^{2}} \frac{b}{2 E} f\left(\alpha_{1}, \alpha_{2}, \xi_{i}\right)$

Substituting this into the crack band propagation condition $\partial W / \partial a=b G_{\mathrm{f}}$, and expressing $G_{\mathrm{f}}$ according to eq. (1), we may calculate $P$ from which we obtain [72]

$\sigma_{\mathrm{N}}=\frac{C_{1} f_{\mathrm{i}}^{\prime}}{1+C_{2} \frac{d}{d_{a}}}$,

in which $C_{1}$ and $C_{2}$ are certain constants characterizing the shape of the structure.

For a sufficiently large structure, 1 is negligible compared to the second term in the denominator, and then $\sigma_{\mathrm{N}}=$ const. $/ \sqrt{d}$. This is the size effect known from linear fracture mechanics. It may be noted that this size effect is obtained by the preceding analysis if item 2 is deleted from our initial hypothesis, i.e., $W$ depends only on $a$.

On the other hand, for a sufficiently small structure, the second term in the denominator is negligible compared to 1 , and then $\sigma_{\mathrm{N}}=C_{1} f_{\mathrm{t}}^{\prime}$. This means that the nominal stress at failure is constant, i.e., there is no size effect, and failure is governed strictly by strength (or yield) condition. It is interesting to note that if item 1 is deleted from our initial hypothesis, i.e., $W$ depends only on the cracked area $A_{c}$, then our preceding analysis yields the constant strength criterion.

In the plot of $\log \sigma_{N}$ versus $\log d$, eq. (5) gives a curve which represents a smooth transition from the strength criteria for small $d$ to the linear elastic fracture mechanics behavior for very large $d$; see fig. 10 .

The preceding analysis of the size effect is of some concern for model tests of PCRVs. Until 1981, a total of 122 scaled model tests of PCRVs had been reported in the literature. Their scales ranged from $1: 3.5$ to $1: 40$, and averaged about $1: 10$. Reduced scale testing is, of course, inevitable, but one must extrapolate reliably to the full scale structures, for which the size effect, above all, needs to be known. It seems that most of these model tests corresponded to the left-hand top part of the curve in fig. 10, for which the strength criterion is adequate. But this does not necessarily mean it is adequate for the actual full-scale structures.

The question is somewhat complicated by the effect of reinforcement that traverses the cracked regions of PCRVs. Some approximate considerations in ref. [72] indicate that as long as the reinforcement in the cracked zone remains elastic, an equation of the type of eq. (5) should still hold, however, with different constants which push the curve in fig. 10 to the right, into larger sizes. 


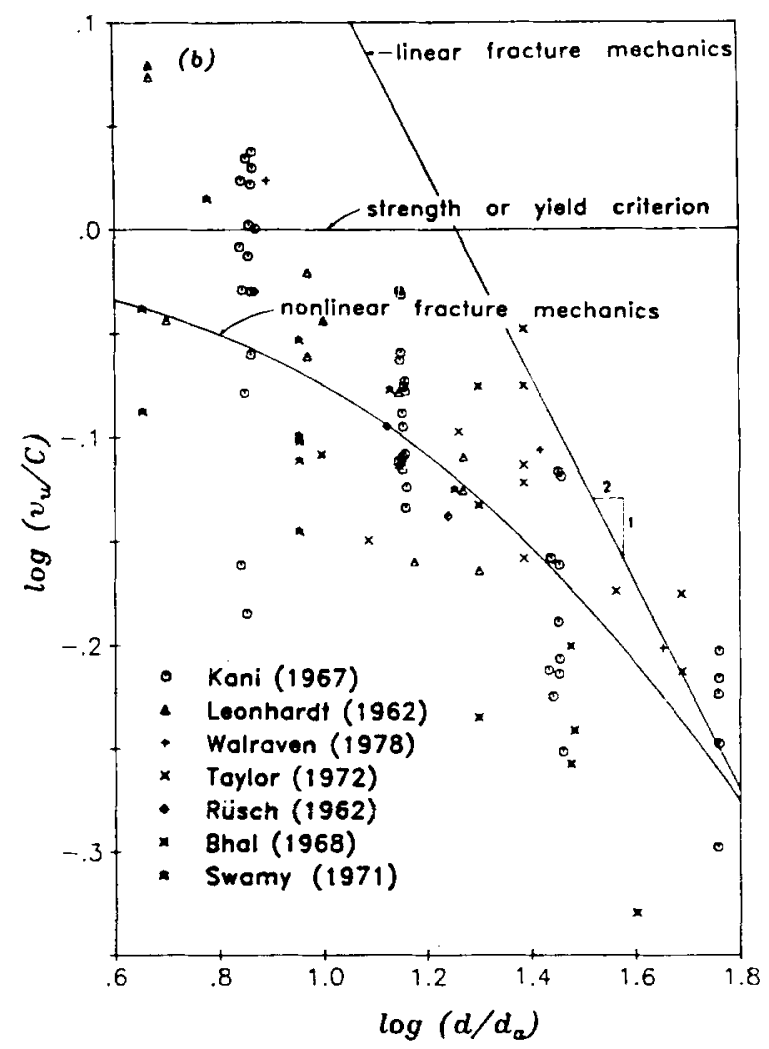

Fig. 11. Plot of nominal shear strength $\sigma_{\mathrm{N}}$ in diagonal shear failure of longitudinally reinforced beams against beam depth $d$ relative to aggregate size $d_{\mathrm{a}}$; data of refs. [65-71]; fit by eq. (5) after ref. [73].

This means that the transition to a fracture mechanicstype size effect occurs later, possibly for structural sizes beyond those of typical PCRVs. Furthermore, if the reinforcement in the cracked zone yields, then there is another transition from the downward sloping curve to a horizontal asymptote. This asymptote roughly corresponds to the plasticity solution based on a zero value for the tensile strength of concrete (a no-tension material) and on yielding of steel. It is, however, very likely that the size effect for PCRVs is not a horizontal straight line through the range of all sizes. Further investigations are needed in this regard, particularly since for some other types of reinforced concrete structures the size effect given by eq. (5) is confirmed by test data.

This confirmation has been obtained by studying available test data for the diagonal shear failure of simply supported beams with longitudinal reinforce- ment but without shear reinforcement. Although most of the test data reported in the literature do not allow the size effect to be judged there exist seven test series which do [65-71]. The results from these tests, analyzed in ref. [73], are plotted in fig. 11, from which the downward trend is clearly apparent, despite the large scatter which is caused by comparing, in the same figure, the test results from different laboratories and for different concretes.

To sum up, the fact that the codes presently used for the analysis of PCRVs do not give correct results for the tensile failure of a plain or reinforced rectangular panel is certainly a matter of concern. So is the fact that the strength criteria used in these codes do not give any size effect.

\subsection{Thermal pore pressure analysis, creep, and probabilistic aspects}

These problems are as important for the analysis of PCRVs as is the analysis of cracking. The scope of this lecture, however, does not allow more than a few comments. Various other references (e.g., [74-76] may be consulted).

The creep analysis of PCRVs in service conditions was being gradually improved over many years, and successively better finite element codes were being developed. The principal difficulty in this analysis is the effect of aging of concrete due to continuing hydration, and the simultaneous effect of temperature on both the aging and the creep rate. At the same time, a conversion must be made from an integral-type creep law based directly on the measured creep curves toa rate-type creep law, which allows a far more efficient computational algorithm.

A finite element program which takes into account aging, the effect of temperature, and a rate-type creep law modeled by the Kelvin chain [80], along with a smeared cracking model based on the strength criterion, was developed by Anderson et al. [77-79]. Recently, a further improvement has been made by developing a finite element program for aging creep based on the Maxwell chain model $[81,82,84]$ which appears to be thermodynamically more correct for a viscoelastic material that undergoes aging [83]. In this program, the temperature effect has been modeled in terms of the physically justified activation energy concept, with one activation energy for the effect of temperature on the rate of aging, and another activation energy for the effect of temperature on the rate of creep $[85,86]$.

A sophisticated subroutine for the input of the creep properties of concrete has been also incorporated in this 
program; see ref. [87] (with errata, 1983 and 1984). This input subroutine permits specifying creep as well as shrinkage either by a set of measured creep compliance values for various load durations and ages at loading, or by the double power law. The material parameters in the double power law are either predicted automatically from the design strength and composition of concrete, or they are obtained by fitting given data by the computer program. If the given creep data are limited, only some parameters are obtained by data fitting while others are predicted from concrete strength and composition. For the analysis of the surface layers of PCRVs one can also specify a decreased pore humidity, and the program automatically formulates its effect on creep properties.

Fig. 12 shows an example of a practical problem which was solved with this program in ref. [85]. A prestressed concrete vessel is considered, prestressed circumferentially and vertically at the age of 180 days, and subjected to an internal surface temperature of
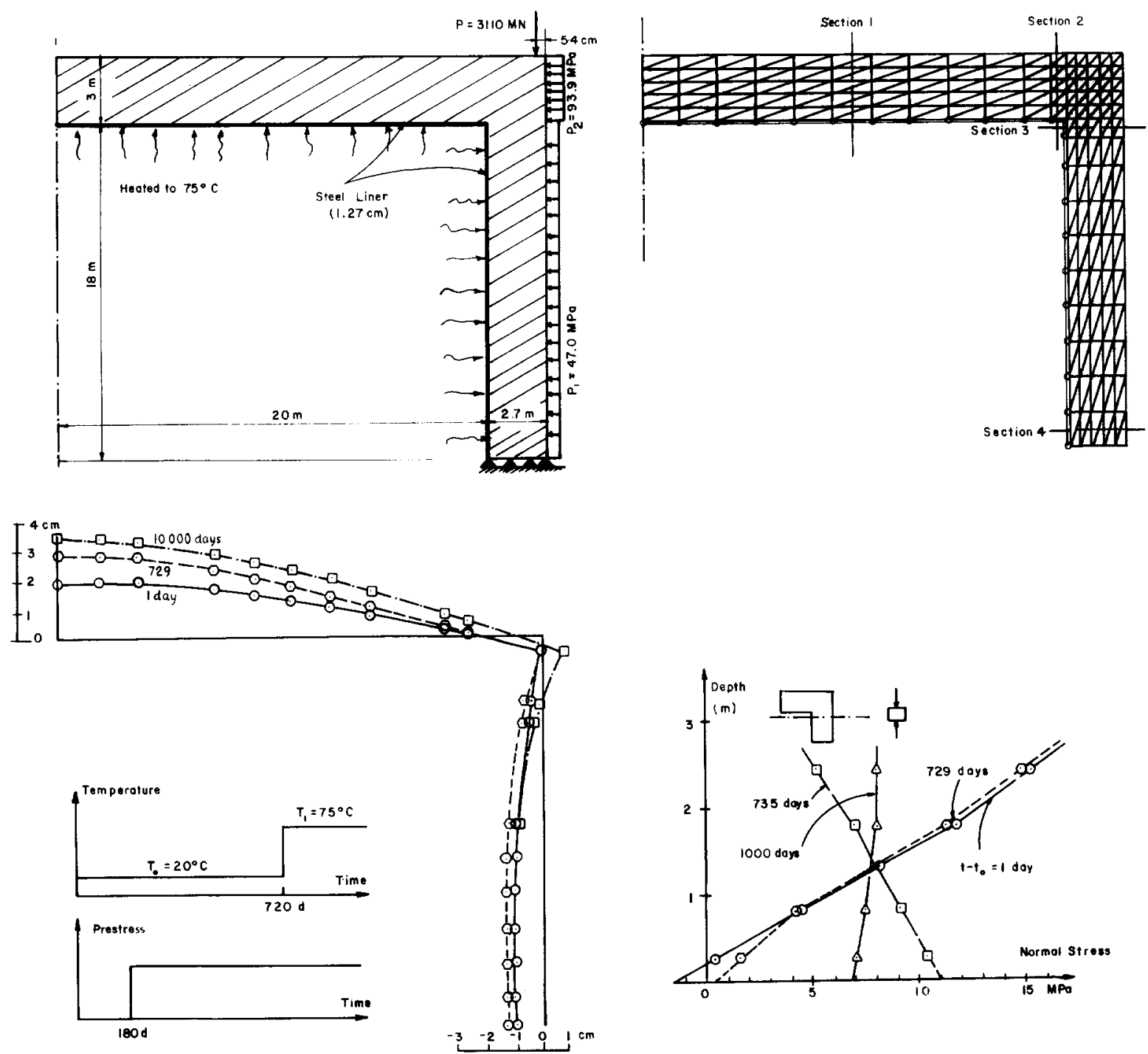

Fig. 12. Example of a finite element creep analysis of a PCRV with age and temperature dependent properties; after Bažant and Rossow [85]. 
$75^{\circ} \mathrm{C}$ at the age of 720 days. Fig. $12 \mathrm{~b}$ shows the finite element mesh used, fig. $12 \mathrm{c}$ shows exaggerated deformations of the central surface of the vessel at several times after the start of heating, and fig. $12 \mathrm{~d}$ shows the distributions of axial normal stress at the horizontal cross section just below the top slab, at various times after the start of heating.

Creep and shrinkage are the most uncertain mechanical properties of concrete. If no tests on the particular concrete to be used in the structure are made (which is not the case for nuclear structures), the uncertainty of creep prediction based on the design strength and composition of concrete is enormous; the $90 \%$ confidence limits for the current ACI Committee 209 recommendation are $\pm 65 \%$ of the creep value, for the current CEB-FIP Model Code $\pm 75 \%$, and for the best prediction model, which is considerably more complicated than the previous two code formulations, $\pm 32 \%[88,89]$.

For a nuclear structure, short-time creep measurements on a limited number of specimens are carried out as a rule. Then the problem is how to extrapolate these data to long times, and how to determine the statistical variability of these extrapolated values. To simply use regression analysis based on the short-time data would not be statistically correct, because these data are too limited for the volume of concrete in the entire structure and do not give sufficient information on the variability to be expected. The proper approach is Bayesian statistics, which takes into account both the prior probability distribution of material parameter values in the creep law, as known for concretes in general on the basis of numerous test data reported in the literature, and updates this distribution on the basis of the limited creep measurements for a given concrete, to obtain a posterior probability distribution for the given structure. Bayesian creep prediction has been recently studied in detail [92], and it has been shown that the coefficients of variation for long-time extrapolations are reduced to approximately one-half compared to prediction without any test data, while they are at the same time larger than those obtained simply by statistical regression. This model also has the feature that the uncertainty (coefficient of variation) is increasing with time, as might be expected.

Random variation of environmental humidity is another statistical influence on creep and shrinkage, which can be handled quite effectively by the spectral method [91]. However, it affects a PCRV wall to a depth of only about $50 \mathrm{~cm}$ from the outer surface, and not even that if the PCRV is surrounded by a containment shell.

Extensive work is being carried out on the problems of calculating water transfer, pore pressures, heat transfer, deformations and creep in concrete heated over $100^{\circ} \mathrm{C}$. Although as many developments could be reported on these questions as on the question of cracking, space limitations require relegating this subject to mere references to recent works [74-76].

Another area of considerable interest for PCRVs is the development of triaxial nonlinear constitutive relations for concrete. Likewise, the space does not permit covering this field.

\section{Conclusions}

As has been seen from this survey, research into technological improvements and methods of analysis of PCRVs continues to be a lively field, with many developments, in spite of the recent set-back in the actual building and orders for these structures. To sum up, technological advances are being made in the design of penetrations and in the design of PCRVs for high temperature exposure as well as exposure to molten sodium or molten core. Serious considerations are being given to applications of PCRVs to other than gas-cooled reactors, particularly to the liquid metal cooled fast breeder reactors. Of great interest is the question of allowing the use of normal concretes at temperatures well over $100^{\circ} \mathrm{C}$, and applying refractory concretes for such exposures to mitigage the effects of accidents.

In the analysis of PCRVs, modeling of cracking and fracture has recently been identified as a problem area. While certain basic principles for the cracking and fracture analysis have been laid down, further work is required to be able to implement more realistic cracking and fracture models in large finite element codes. Progress continues to be made in creep analysis for service conditions, with aging and temperature effects being taken into account. Finally, an active and very important area is the analysis of heat transfer, water transfer and pore pressures in concrete rapidly heated to high temperatures, and the deformations with creep under such conditions. Further significant advances, which will lead to significant improvements of the already mature technology of PCRVs, may be expected.

\section{Acknowledgment}

Partial financial support under US National Science Foundation Grant No. CEE-8303148 is gratefully acknowledged. Mary Hill deserves an expression of appreciation for her perfect and prompt secretarial assistance. 


\section{References}

[1] G. Lamiral and J. Courbon, Les caissons en béton précontraint dans les centrales nucléaires d'EDF 3 et d'EDF4, Annales de l'Institut Technique du Bâtiment et des Travaux Publics, Vol. 18, No. 206 (February 1965) pp. 207-232.

[2] E. Robert and P. Launay, Le caisson en béton précontraint de la centrale nucléaire Bugey I, Travaux (October 1966) pp. 1143-1150.

[3] P. Launay, Etude et construction du caisson en béton précontraint de la centrale nucléaire de Bugey I, 6th FPI Congress, Prague (June 1970).

[4] D.J. Naus, Prestressed concrete pressure vessels and their ability to advanced energy system concepts, Conference on Pressure Vessels and Piping, ASME, Portland, Oregon, Paper 83-NE-1 (June 1983) pp. 1-6.

[5] Conf. on Prestressed Concrete Pressure Vessels, held in London, March 1967 (Institution of Civil Engrs., 1960).

[6] D.J. Naus, Prestressed concrete reactor vessel research and development studies at the Oak Ridge National Laboratory, Proc. of the Conference of Gas-cooled Reactors Today (British Nuclear Energy Society, London, September 1982) pp. 173-178.

[7] S.R. Speidel and W.H. Plattenberg, Development of a removable closure for large cavities in high temperature reactor PCRVs, Nucl. Technol. 49 (1980) 61-69.

[8] D.J. Naus, A review of prestressed concrete reactor vessel related structural model tests, ORNL/GUR-80/10, contract No. W-7405-eng-2b, Oak Ridge National Laboratory Gas-cooled Reactor Programs, Oak Ridge National Laboratory, Oak Ridge, Tennessee (October 1980) pp. 91.

[9] D.J. Naus, A summary of research and development activities conducted under the prestressed concrete pressure vessel (PCPV) program in support of energy systems development, ORNL/GUR-81/7, Contract No. W-7405eng-2b, Oak Ridge National Laboratory Gas-cooled Reactor Programs, Oak Ridge National Labaratory, Oak Ridge, Tennessee (July 1981) pp. 40.

[10] D.J. Naus, Steel reinforcement and prestressing for prestressed concrete pressure vessels, ORNL/GCR-80/28, Contract No. Wl-7405-eng-2b, Oak Ridge National Laboratory Gas-cooled Reactor Programs, Oak Ridge National Laboratory, Oak Ridge, Tennessee (December 1980) pp. 105.

[11] H. Ashar and D.J. Naus, Overview of the use of prestressed concrete in US nuclear power plants, 7 th Int. Conf. on Structural Mechanics in Reactor Technology, Paper $\mathbf{H}$ 1/1, Vol. H, pp. 1-10.

[12] D.J. Naus, An evaluation of pressure vessel concepts for application to high-temperature gas-cooled reactor systems, ORNL/GCR-82/12, Contract No. W-7405-eng-2b, Oak Ridge National Laboratory Gas-cooled Reactor Programs, Oak Ridge National Laboratory, Oak Ridge, Tennessee (July 1982) pp. 69.

[13] D.J. Naus, Task 2: Concrete properties in nuclear environment - a review of concrete material systems for application to prestressed concrete pressure vessels, ORNL/TM-
7632, Contract No. W-7405-eng-2b, Engineering Technology Division, Oak Ridge National Laboratory, Oak Ridge. Tennessee (May 1981) pp. 125.

[14] R.A. Moore, M.E. Kantor, H.L. Brey and H.G. Olson, HTGR Experience, Programs and Future Applications. Nucl. Engrg. Des. 72 (1982) 153-174.

[15] C. Elter and G. Becker, Design criteria for prestressed concrete reactor vessels for high temperature reactors, Nucl. Technol. 59 (1982) 228-233.

[16] Concrete for Nuclear Reactors, Am. Concrete Institute Special Publ. SP34, Detroit (1972).

[17] Preprints of Int. Conf. on Structural Mechanics in Reactor Technology, No. 1-No. 7, 1971-1983 (Commission of European Communities, Brussels).

[18] H.G. Olson, H.L. Brey and F.E. Swart, The Fort St. Vrain high temperature gas-cooled reactor: VII. Prestressed concrete reactor vessel (PCRV) performance, Nucl. Engrg. Des. 72 (1982) 111-123.

[19] G.C. Robinson, W.G. Dodge and J.P. Callahan, GCFR 1/15-scale PCRV steam generator cavity closure halfthickness model test, Report ORNL/TM-6461 (UC-77, Contract W-7405-eng. 26), Oak Ridge National Laboratory, Oak Ridge, Tennessee (December 1978).

[20] Code for Concrete Reactor Vessels and Containments, ASME Boiler and Pressure Vessel Code, Sec. 3, Div. 2, and ACI Standard 359-74, Am. Soc. of Mechanical Engineers, New York (1975).

[21] British Standard 4975, Specifications for prestressed concrete pressure vessels for nuclear reactors (British Standard Institution, 1973).

[22] Z.P. Bažant, Safety advantages of prestressed concrete reactor vessels, Nucl. Technol. (Am. Nuclear Society) 10 (1976) 156-160.

[23] Z.P. Bažant, A.H. Marchertas and R.W. Seidensticker, Design of Top Closures of Concrete Reactor Vessels with Very High Energy Absorption Capability, Proc. 6th Int. Conf. on Struct. Mech. in Reactor Technology, held in Paris (1981) Paper H2/6.

[24] J. Német, H. Koop, A. Jungmann and L. Zwingenberger, Safety design of a PCRV with hot liner and elevated wall temperature, 3rd Int. Conf. Structural Mechanics in Reac. tor Technology, H 3/3, London' (1975).

[25] H. Zemann and R. Angelei, The instrumentation of the prestressed concrete pressure vessel with hot liner at Seibersdorf Research Centre, 3rd Int. Conf. Structural Mechanics in Reactor Technology, H 3/10, London (1975).

[26] K. Schimmelpfennig, Untersuchungen zum Verhalten eines HTR-Spannbetonbehälters bei extremen Core-temperaturen, Konstruktiver Ingeniernbau, Heft 38/39 (December 1981) pp. 88-95.

[27] K. Schimmelpfennig, Special aspects of the behavior of PCRV under extremely high core temperature loading, SMiRT7, Chicago (August 1983), Paper H2/1.

[28] U. Schneider, U. Diederichs and C. Ehm, Effect of temperature on steel and concrete for PCRVs, Nucl. Engrg. Des. 67 (1981) 245-258.

[29] Z.P. Bažant and S.H. Fistedis, Dried hot concrete vessel 
for nuclear reactors: proposal of a new design concept, Nucl. Engng. Des. 26 (1978) 317-324.

[30] R.W. Seidensticker, L.I. Cheng, G.N. Freskakis and S.N. Pagay, Significant structural design features of commercial-sized liquid-metal fast breeder reactor (LMFBR) plant, Nucl. Engng. Des. 73 (1982) 13-22.

[31] A. Skokan, H. Holleck and M. Peehs, Chemical Reactions between Light-Water Reactor Core Melt and Concrete, Nucl. Technol. 46 (1979) 255-273.

[32] H.J. Sutherland, J.E. Smaardyk and L.A. Kent, Acoustic measurement of penetration of liquid sodium into limestone concrete, Nucl. Technol. 49 (1980) 70-91.

[33] Z.P. Bažant, J.C. Chern, M.S. Abrams and M.P. Gillen, Normal and refractory concrete, for LMFBR applications - vol. 1, Review of literature on high-temperature behavior of Portland cement and refractory concretes, Vol. 2, Evaluation of concrete for LMFBR applications, EPRI Final Report NP-2437 (Projects 1704-14, 1706-19) El. Power Research Institute, Palo Alto, Cal. (June 1982).

[34] Z.P. Bažant, J.C. Chern, R.W. Seidensticker and A.H. Marchertas, Design of prestressed concrete pressure vessel for use in primary and secondary containment of LMFBR plants, Proc. 6th Int. Conf. on Struct. Mech. in Reactor Technology, held in Paris (1981), Paper H2/2.

[35] D. Swenson, Analysis of sodium spills onto basalt concrete crucible and containment cell, Sandia Laboratories, No. 0763.610 (November 1979).

[36] J.A. Hassberger, R.K. Hilliard and L.D. Muhlestein, Sodium-concrete reaction tests, HEDL-TME-74-36 (1974).

[37] J.A. Hassberger, Intermediate scale sodium-concrete reaction tests, HEDL-TME-77-99 (1978).

[38] J.A. Hassberger, Intermediate-scale sodium-concrete reaction tests with basalt and limestone concrete, HEDLTME-79-55 (1980).

[39] D.G. Swanson and H.L.L. van Paasen, Evaluation of materials interaction for advanced reactor systems, NUREB/CR-512, Annual Progress Report, The Aerospace Corporation (November 1980).

[40] M.W. McCormick, L.D. Muhlestein, R.P. Colburn and B.V. Winkle, Large-scale sodium-basalt concrete reaction test, LSC-1, HEDL-TME 80-57 (August 1980), Preliminary Draft.

[41] A.J. Mahncke et al., Sodium-concrete tests with faulted cell liners, HELD-TME-79-49 (1980).

[42] R.K. Hilliard and W.D. Boehmer, Concrete protection from sodium spills by intentionally defected liners small-scale test $\mathbf{S} 9$ and S10, HEDL-TME-75-75 (July 1975).

[43] J.K. Fink, J.J. Heiberger, R. Kumar and R.A. Blomquist, Interactions of refractories and reactor materials with sodium, Nucl. Technol. 35 (1977) 656.

[44] C. Casselman, Consequences of interaction between sodium and concrete, Nucl. Engrg. Des. 68 (1981) 207-212.

[45] Y.R. Rashid, Analysis of prestressed concrete pressure vessels, Nucl. Engng. Des. 7 (1968) 334-344.

[46] Z.P. Bažant and L. Cedolin, Blunt crack band propagation in finite element analysis, J. Engng. Mech. Div., Proc. ASCE, 105 (1979) 297-315.
[47] L. Cedolin and Z.P. Bažant, Effect of finite element choice in blunt crack band analysis, Computer Meth. Appl. Mech. Engng. 24 (1980) 305-316.

[48] Z.P. Bažant and L. Cedolin, Fracture mechanics of reinforced concrete, J. Engrg. Mech. Div., Proc. ASCE, 106 (1980) 1287-1306.

[49] Z.P. Bažant and L. Cedolin, Finite element modeling of crack band propagation, J. Structural Engrg., ASCE, 109, No. ST2 (1983) 69-92.

[50] Z.P. Bažant, Mechanics of fracture and progressive cracking in concrete structures, in: Fracture Mechanics Applied to Concrete Structures, ed., G.C. Sih (Martinus Nijhoff Publishers B.V., The Hague, Netherlands), in press.

[51] L. Cedolin and Z.P. Bažant, Fracture mechanics of crack bands in concrete, Fracture Mech. Methods for Ceramics, Rocks and Concrete, eds., S.W. Freiman and E.R. Fuller, Am. Soc. for Testing Materials STP 745 (1981).

[52] R.H. Evans and M.S. Marathe, Microcracking and stress-strain curves for concrete in tension, Materials and Structures, No. 1 (RILEM, Paris, 1968) pp. 61-64.

[53] H.G. Heilmann, H.H. Hilsdorf and K. Finsterwalder, Festigkeit und Verformung von Beton unter Zugspanungen, Deutscher Ausschuss für Stahlbeton, Heft 203 (W. Ernst \& Sohn, West Berlin, 1969).

[54] H. Rüsch and H. Hilsdorf, Deformation Characteristics of Concrete under Axial Tension, Voruntersuchungen, Bericht Nr. 44, Munich (May 1963).

[55] B.P. Hughes and G.P. Chapman, The complete stress-strain curve for concrete in direct tension, No. 30 (RILEM, Paris, 1966) pp. 95-97.

[56] P.F. Petersson, Crack growth and development of fracture zones in plain concrete and similar materials, Doctoral Dissertation, Lund Institute of Technology, Lund, Sweden (1981).

[57] Z.P. Bažant, Crack band model for fracture of geomaterials, Proc. 4th Int. Conf. on Numerical Methods in Geomechanics, held in Edmonton, Alberta, Canada, June 1982, ed., Z. Eisenstein, Vol. 3., pp. 1137-1152.

[58] Z.P. Bažant and B.H. Oh, Crack band theory for fracture of concrete, Materials and Structures, Vol. 16 (RILEM, Paris, 1983) pp. 155-177.

[59] Z.P. Bažant and B.H. Oh, Microplane model for fracture analysis of concrete structures, Proc. Symp. Interaction of Nonnuclear Munitions with Structures, US Air Force Academy, Colorado Springs (May 1983) pp. 49-55.

[60] S. Mindess and S. Diamond, A preliminary SEM study of crack propagation in mortar, Cement and Concrete Research 10 (1980) 509-519.

[61] L. Cedolin, S. Dei Poli and L. Iori, Experimental determination of the fracture process zone in concrete, Cement and Concrete Research 13 (1983) to appear.

[62] L. Cedolin, S. Dei Poli and L. Iori, Experimental determination of the stress-strain curve and fracture zone for concrete in tension, Proc. Int. Conf. on Constitutive Laws for Engineering Materials, ed. C. Desai, University of Arizona, Tucson (January 1983).

[63] Y.C. Pan, A.H.Marchertas and J.M. Kennedy, Finite element of blunt crack band propagation, A Modified J-In- 
tegral Approach, Preprints, 7th Int. Conf. on Structural Mechanics in Reactor Technology, Paper H, Chicago (August 1983).

[64] A.H. Marchertas, R.F. Kulak and Y.C. Pan, Performance of blunt crack approach within a general purpose code, in: Nonlinear Numerical Analysis of Reinforced Concrete, ed., L.E. Schwer, Am. Soc. of Mech. Engrs., New York 1982 (presented at ASME Winter Annual Meeting, Phoenix, Nov. 1982) pp. 107-123.

[65] G.N.J. Kani, Basic factors concerning shear failure, Part I and Part II, J. ACI 63 (June 1966) 675-692.

[66] F. Leonhardt and R. Walther, Beiträge zur Behandlung der Schubprobleme im Stahlbetonbau, Beton-u Stahlbetonbau, Vol. 56, No. 12 (1961); Vol. 57 Nos. 2, 3, 6, 7, 8, (1962); Vol. 58, No. 8, 9 (1963).

[67] N.S. Bhal, Über den Einfluss der Balkenhöhe auf Schubtragfahigkeit von eifeldrigen Stahlbetonbalken mit und ohne Schubbewehrung, Dissertation, Universität Stuttgart (1968)

[68] J.C. Walraven, The influence of depth on the shear strength of lightweight concrete beams without shear reinforcement, Stevin Laboratory Report No. 5-78-4, Delft University of Technology (1978).

[69] H.P.J. Taylor, The shear strength of large beams, J. Structural Division ASCE 98 (1972) 2473-2490.

[70] M. Rüsch, F.R. Haugli and M. Mayer, Schubversuche an Stahlbeton Rechteckbalken mit gleichmässig verteilter Belastung, Deutscher Ausschuss für Stahlbeton, Heft 145 W. Ernst u. Sohn, West Berlin (1962).

[71] R.N. Swamy and S.A. Qureshi, Strength, cracking and deformation similitude in reinforced $\mathrm{T}$-beams under bending and shear, Part I and II, J. Am. concrete Inst. 68 (1971) 186-195.

[72] Z.P. Bažant, Size effect in brittle failure of concrete structures, Report No. 83-2/665s, Center for Concrete and Geomaterials, Northwestern University, Evanston, Illinois (February, 1983); Size effect in blunt fracture: concrete, rock, metal, J. Engrg. Mech., ASCE, in press.

[73] Z.P. Bažant and J.K. Kim, Size effect in shear failure of longitudinally reinforced beams, Report No. 83-5/428s, Center for Concrete and Geomaterials, Northwestern University, Evanston, Illinois (May 1983); J. Am. Concrete Institute, in press.

[74] Z.P. Bažant, J.C. Chern and W. Thonguthai, Finite element program for moisture and heat transfer in heated concrete, Nucl. Engrg. Des. 68 (1981) 61-70.

[75] Z.P. Bažant, Mathematical model for creep and thermal shrinkage of concrete at high temperature, Nucl. Engrg. Des. 76 (1983) 183-191.

[76] S. Thelandersson, On the multiaxial behavior of concrete exposed to high temperature, Paper $\mathrm{H} 3 / 1$, presented at 7th Int. Conf. on Struct. Mech. in Reactor Technology, Chicago (August 1983); Nucl. Engrg. Des. to appear.

[77] C.A. Anderson, Numerical creep analysis of structures, Los Alamos Scientific Laboratory Rep. LA-UR-80-2585 (1980); Z.P. Bažant and F.H. Wittmann, eds., Creep and Shrinkage in Concrete Structures (Wiley, New York) pp. 259-303.
[78] P.D. Smith, W.A. Cook and C.A. Anderson, Finite element analysis of prestressed concrete reactor vessels, Proc. 4th Int. Conf. on Structural Mechanics in Reactor Technology, San Francisco, Ca.

[79] P.D. Smith and C.A. Anderson, NONSAP-C: a nonlinear stress analysis program for concrete containments under static, dynamic, and long-term loadings, Los Alamos Sci. Lab. Rep. LA-7496-MS.

[80] Z.P. Bažant and S.T. Wu, Dirichlet series creep function for aging concrete, J. Eng. Mech. Div. ASCE, 99, No. EM2, Proc. Paper 9645.

[81] Z.P. Bažant and S.T. Wu, Rate-type creep law of aging concrete based on Maxwell chain, Materials and Structures (RILEM, Paris) pp. 45-60.

[82] Z.P. Bažant, Mathematical models for creep and shrinkage of concrete, in: Creep and Shrinkage in Concrete Structures, eds. Z.P. Bažant and F.H. Wittmann (Wiley New York, 1982), pp. 163-258.

[83] Z.P. Bažant and S.T. Wu, Thermoviscoelasticity of aging concrete, J. Eng. Mech, Div. ASCE, 100, 575-597; ASCE Preprint 2110.

[84] ASCE State-of-the-Art Report on Finite element analysis of reinforced concrete, prepared by a Task Committee chaired by A. Nilson, Am. Soc. of Civil Engrs., New York (1982).

[85] Z.P. Bažant and E.C. Rossow, CREEP80-axisymmetric finite element program for creep analysis of aging concrete structures at variable temperature, Report No. 81-8A to Oak Ridge National Laboratory, Tennessee, Aug. 1981 (available from NTIS, Springfield, Virginia).

[86] Z.P. Bažant, E.C. Rossow and G. Horrigmoe, Finite element program for creep analysis of concrete structures, Proc. 6th Int. Conf. on Structural Mechanics in Reactor Technology, Paris, Paper H2/1.

[87] Z.P. Bažant, Input of creep and shrinkage characteristics for a structural analysis program, Materials and Structures Vol. 15, No. 88 (RILEM, Paris, 1982) pp. 283-290, with Errata 193 and 1984.

[88] Z.P. Bažant and L. Panula, Practical prediction of time-dependent deformations of concrete, Materials and Structures (RILEM, Paris, 1978), pp. 307-328; 415-434; vol. 12 (1979) pp. 169-183 (with Errata 1980).

[89] Z.P. Bažant and L. Panula, Creep and shrinkage characterization for prestressed concrete structures, J. Prestressed Concrete Institute 25 (1980) 86-122.

[90] H.O. Madsen and Z.P. Bažant, Uncertainty analysis of creep and shrinkage effects in concrete structures, American Concrete Institute J. 80 (1983) 116-127.

[91] Z.P. Bažant, Probabilistic problems in prediction of creep and shrinkage effects in structures, Proc. Int. Conf. on 4th Int. Conf. on Applications of Statistics and Probability in Soil and Structural Engrg. Universita di Firenze, Florence, Italy (June 1983) pp. 325-356

[92] Z.P. Bažant and J.C. Chern, Bayesian statistical prediction of concrete creep and shrinkage, J. Am. Concrete Institute (in press). 